\title{
The Effect of Solid-State Processes and Heat Treatment on the Properties of AA7075 Aluminum Waste Recycling Nanocomposite
}

\author{
Huda Mohammed Sabbar ${ }^{1, *}$, Zulkiflle Leman ${ }^{1,2,3, * \mathbb{D}}$, Shazarel Shamsudin ${ }^{4}$, Suraya Mohd Tahir ${ }^{1}$, \\ Che Nor Aiza Jaafar ${ }^{1}$, Azmah Hanim Mohamed Ariff ${ }^{1}{ }^{1}$, Nur Ismarrubie Zahari ${ }^{1}$ and Mohammed H. Rady ${ }^{5}$ \\ 1 Department of Mechanical and Manufacturing Engineering, Faculty of Engineering, Universiti Putra \\ Malaysia, Serdang 43400, Malaysia; su_mtahir@upm.edu.my (S.M.T.); cnaiza@upm.edu.my (C.N.A.J.); \\ azmah@upm.edu.my (A.H.M.A.); rubie@upm.edu.my (N.I.Z.) \\ 2 Advanced Engineering Materials and Composites Research Centre, Faculty of Engineering, Universiti Putra \\ Malaysia, Serdang 43400, Malaysia \\ 3 Laboratory of Biocomposite Technology, Institute of Tropical Forestry and Forest Products, Universiti Putra \\ Malaysia, Serdang 43400, Malaysia \\ 4 Sustainable Manufacturing and Recycling Technology, Advanced Manufacturing and Materials \\ Centre (SMART-AMMC), Universiti Tun Hussein Onn Malaysia, Batu Pahat 86400, Malaysia; \\ shazarel@uthm.edu.my \\ 5 College of Engineering, Wasit University, Kut 52001, Iraq; mradhi@uowasit.edu.iq \\ * Correspondence: hudasabbar86@gmail.com (H.M.S.); zleman@upm.edu.my (Z.L.)
}

\section{check for} updates

Citation: Sabbar, H.M.; Leman, Z.; Shamsudin, S.; Tahir, S.M.;

Jaafar, C.N.A.; Ariff, A.H.M.; Zahari, N.I.; Rady, M.H. The Effect of Solid-State Processes and Heat Treatment on the Properties of AA7075 Aluminum Waste Recycling Nanocomposite. Materials 2021, 14, 6667. https://doi.org/10.3390/ ma14216667

Academic Editor: Arman Shojaei

Received: 27 September 2021

Accepted: 1 November 2021

Published: 5 November 2021

Publisher's Note: MDPI stays neutral with regard to jurisdictional claims in published maps and institutional affiliations.

Copyright: (c) 2021 by the authors. Licensee MDPI, Basel, Switzerland. This article is an open access article distributed under the terms and conditions of the Creative Commons Attribution (CC BY) license (https:// creativecommons.org/licenses/by/ $4.0 /)$.

\begin{abstract}
Direct solid-states, such as hot extrusion and equal channel angular pressing (ECAP), are alternative and efficient solid-state processes for use in recycling aluminium scrap. These processes utilise less energy and are eco-friendly. Ceramic particles such as $\mathrm{ZrO}_{2}$ are suggested as alternatives in the production of metal composites. This study investigated and optimised the effects of various parameters of reinforced $\mathrm{ZrO}_{2}$ nanoparticles on the mechanical and physical properties via response surface methodology (RSM). These parameters were the volume fraction (VF), preheating temperature $(\mathrm{T})$, and preheating time $(\mathrm{t})$. The effects of these parameters were examined before and after the heat treatment condition and ECAP. Each parameter was evaluated at varying magnitudes, i.e., 450,500 , and $550{ }^{\circ} \mathrm{C}$ for $\mathrm{T}, 1,2$, and $3 \mathrm{~h}$ for $\mathrm{t}$, and 1, 3, and $5 \%$ for VF. The effect that process variables had on responses was elucidated using the factorial design with centre point analysis. $\mathrm{T}$ and VF were crucial for attaining the optimum ultimate tensile strength (UTS) and microhardness. Reducing VF increased the mechanical properties to $1 \mathrm{vol} \%$ of oxide. The maximum hardness of $95 \mathrm{HV}$ was attained at $550{ }^{\circ} \mathrm{C}, 1.6 \mathrm{~h}$, and $1 \mathrm{vol} \% \mathrm{ZrO}_{2}$ with a density of $2.85 \mathrm{~g} / \mathrm{cm}^{3}$ and tensile strength of $487 \mathrm{MPa}$. UTS, density, and microhardness were enhanced by $14 \%, 1 \%$, and $9.5 \%$, respectively. Additionally, the hot extrusion parameters and ECAP followed by heat treatment strengthened the microhardness by $64 \%$ and density by $3 \%$. Compression pressure and extrusion stress produced in these stages were sufficient to eliminate voids that increased the mechanical properties.
\end{abstract}

Keywords: aluminium alloy AA7075; ECAP; heat treatment; hot extrusion; $\mathrm{ZrO}_{2}$

\section{Introduction}

Conventionally, the recycling of aluminium scraps is carried out through re-melting at high temperatures with the recovery of most of the materials [1]. However, the loss of materials and the high-energy requirement in the conventional recycling method [2] have encouraged the development of eco-friendly and economically viable methods to address the environmental issues of air pollution. This method, broadly known as solid-state recycling, involves the direct treatment of alloy chips [3,4]. Solid-state recycling, such as hot extrusion and ECAP, optimises energy, using the plastic deformation technique to recycle metal scraps and various alloys [5-7]. Furthermore, heat treatment after solid-state 
recycling, i.e., hot extrusion, improves the mechanical properties of the alloy with the formation of secondary phases and the homogeneous distribution of fine precipitates [6]. The hot extrusion solid-state recycling process not only conserves the environment but also prevents the generation of new waste material [7].

Meanwhile, the technique of ECAP is used to improve the effect of reinforcement on the properties of light metals and alloys of aluminium, copper, and titanium. The ECAP technique produces composite materials with high mechanical properties to enhance the properties of billets. In general, studies on ECAP focused on metallic alloys, pure metals, and plastic deformation [8]. For example, processing metal matrix composite (MMC) materials through extrusion or ECAP has been widely used to manufacture ultrafinegrained structures for various engineering materials.

This research study uses extrusion along with ECAP to recycle metal matrix composites (MMCs). The most common SPD technique is ECAP, which uses the ECAP die with different angles [9]. Apparently, the ECAP technique is flexible and has been deployed in combination with hot extrusion. This informed the choice of ECAP in combination with hot extrusion in the current study.

The physical and mechanical properties and microstructure of products extruded using the solid-state recycling of aluminium alloy chips are dependent on the number of hot extrusion parameters [10]. Temperature-related parameters, the extrusion ratio, die geometry, chip morphology, and ram speed are relevant factors that need to be well regulated to obtain qualitative products from the recycling process [11,12].

This research intends to propose a new approach to improve the performance of aluminium composites made of chips with the addition of $\mathrm{ZrO}_{2}$ particles. Moreover, the chip-based composite-reinforced $\mathrm{ZrO}_{2}$ contents offer alternative sources to manufacturing automotive industries to recycle, reuse the machined materials as a secondary source of metal, and protect our earth from greenhouse gas for a sustainable life. This study focused on examining the effects of preheating time $(\mathrm{t})$, preheating temperature $(\mathrm{T})$, and volume fraction (VF) on the mechanical and physical properties of a $\mathrm{ZrO}_{2}$ aluminium chips nanocomposite. This nanocomposite was produced through the hot extrusion method followed by ECAP to compare the result with heat treatment. The influence of each factor was analysed using the factorial design, followed by RSM. The microstructure and the average grain sizes of the extrudates were also investigated.

\section{Materials and Methods}

Fabrication of Hybrid Aluminium Nanocomposite

Samples of recycled MMC chips were fabricated with the addition of AA7075 aluminium chips and $\mathrm{ZrO}_{2}$ particles to enhance the mechanical and physical properties of the alloy. $\mathrm{ZrO}_{2}$ nanoparticles were added due to their robust mechanical and electrical properties, good wear resistance and corrosion resistance, and a wide bandgap. The sizes of the AA7075 chips (Table 1) were verified using a digital venire calliper. Table 2 shows the chemical composition of the AA7075 samples.

Table 1. Aluminium AA7075 chips' sizes.

\begin{tabular}{ccccc}
\hline Dimension & Chip 1 & Chip 2 & Chip 3 & Chip 4 \\
\hline Width $(\mu \mathrm{m})$ & 67.7 & 58 & 44 & 56.5 \\
Thickness $(\mathrm{mm})$ & 0.049 & 0.074 & 0.067 & 0.063 \\
Length $(\mathrm{mm})$ & 3.42 & 3.1 & 3.5 & 3.34 \\
\hline
\end{tabular}


Table 2. AA7075 aluminium chemical composition in wt.\%.

\begin{tabular}{ccc}
\hline Element & Percent (wt.\%) & Atomic Mass (u) \\
\hline $\mathrm{Si}$ & 0.1 & 27.97 \\
$\mathrm{Fe}$ & 0.19 & 55.84 \\
$\mathrm{Cu}$ & 1.53 & 63.54 \\
$\mathrm{Mg}$ & 2.55 & 24.3 \\
$\mathrm{Zn}$ & 5.89 & 65.38 \\
$\mathrm{Mn}$ & 0.07 & 54.93 \\
$\mathrm{Cr}$ & 0.18 & 51.99 \\
$\mathrm{Ni}$ & 0.0058 & 58.69 \\
$\mathrm{Ti}$ & 0.024 & 47.86 \\
$\mathrm{Al}$ & $\mathrm{Bal}$ & 26.98 \\
\hline
\end{tabular}

In the fabrication, the AA7075 aluminium alloy chips were snipped using a computer numerical control $(\mathrm{CNC})$ machine with a depth cut of $1 \mathrm{~mm}$. Following the standard method of the American Society for Testing and Materials (ASTM) G131-96, the chips were degreased with acetone in an ultrasonic bath for $30 \mathrm{~min}$ to remove the contaminants of the coolant oil and other substances. The chips were dried at $80^{\circ} \mathrm{C}$ for $30 \mathrm{~min}$ thenmixed separately with $1 \%, 3 \%$, and $5 \% \mathrm{ZrO}_{2}$ nanoparticles using a three-dimensional (3D) mixer (SYH-15), China. for $2 \mathrm{~h}$ at the speed of $35 \mathrm{rpm}$. Billets were formed using cold compaction in a cylindrical die with a diameter of $30 \mathrm{~mm}$ and a length of $100 \mathrm{~mm}$ with a pressing force of $50 \mathrm{kN}$.

FESEM-EDX were used in the study of the morphology of $\mathrm{ZrO}_{2}$ particle (Suzhou Beike Technology Co., Suzhou, China) shape and size with the magnification of $\times 100,000$ (Figure 1 shows the particle sizes of $\mathrm{ZrO}_{2}$, ranging from 70 to $211 \mathrm{~nm}$ ). They deviated slightly from previous findings due to the inefficient dispersion of the powder during particle size analysis in this study. The purity of the reinforcement (Table 3) shows the EDX analysis (Figure 2) of the $\mathrm{ZrO}_{2}$ nanopowder, confirming the presence of $\mathrm{Zr}$ and $\mathrm{O}$.

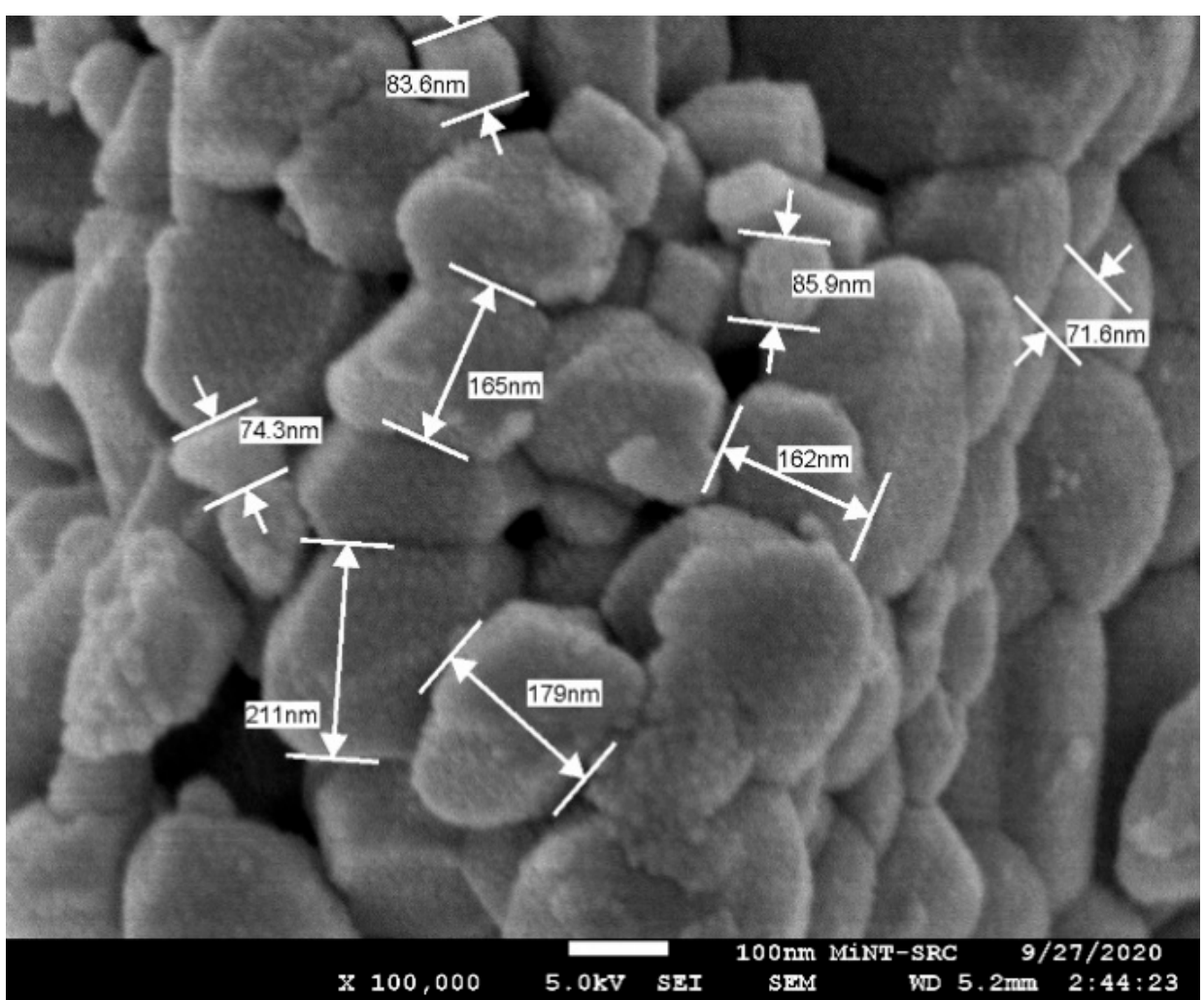

Figure 1. $\mathrm{ZrO}_{2}$ nanoparticle size and shape. 
Table 3. The EDX analysis of the $\mathrm{ZrO}_{2}$ nano powder.

\begin{tabular}{cccc}
\hline Reinforcement & Element & Weight $\%$ & Atomic\% \\
\hline \multirow{2}{*}{$\mathrm{ZrO}_{2}$} & $\mathrm{O} \mathrm{K}$ & 25.27 & 65.85 \\
\cline { 2 - 4 } & $\mathrm{Zr} \mathrm{L}$ & 74.73 & 34.15 \\
\cline { 2 - 4 } & Total & 100 & - \\
\hline
\end{tabular}

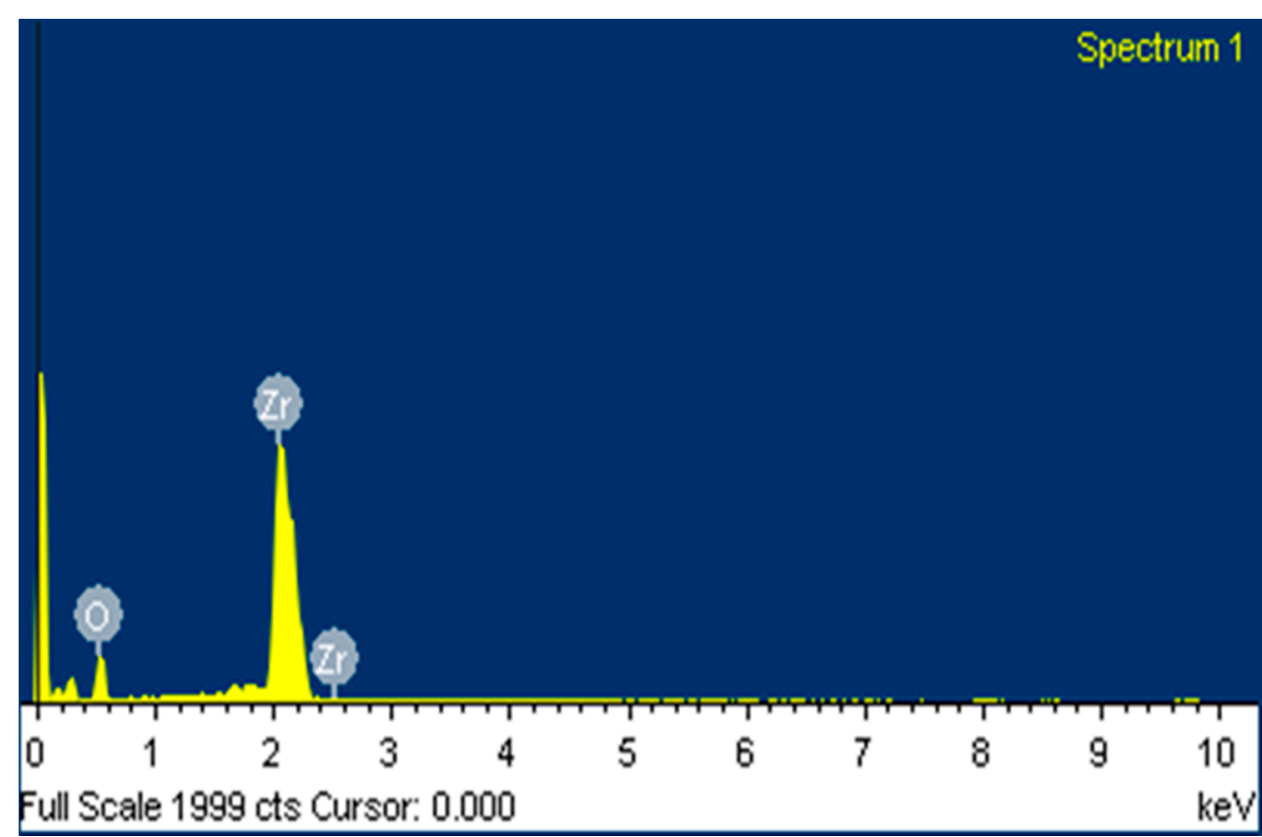

Figure 2. $\mathrm{ZrO}_{2}$ nanoparticle EDX.

Minitab 18 software was used to perform RSM. The experimental design of the research was performed in the full factorial design, where the three main parameters were $1-5 \%$ vol $\mathrm{ZrO}_{2}$-reinforced nanoparticle, a 1-3 h time period and a temperature of $450-550{ }^{\circ} \mathrm{C}$; these processing values were applied. In this work, the experiment's design was intended to help develop the optimisation and proposal of MMC composites. The best overall optimum parameters, such as particles and processing temperature, were investigated. Then, the RSM model Equation (1) was suggested as the sufficiency, and the linear model was capable of defining the relationship between the response or other process factors in the process.

$$
y=b_{0}+b_{1} X_{1}+b_{2} X_{2}+\cdots+b_{k} X_{k}
$$

In the regression equation, $y$ is the response variable, $b_{0}$ is the constant, $b_{1}, b_{2}, \ldots, b_{k}$ are the coefficients, and $X_{1}, X_{2}, \ldots, X_{k}$ are the values of the terms.

Parameters such as preheating temperatures, compositions of the aluminium chip, and $\mathrm{ZrO}_{2}$ reinforcement materials are shown in Table 4.

Table 4. The design scheme of the process parameters.

\begin{tabular}{ccccc}
\hline \multirow{2}{*}{ Factor Symbol } & \multirow{2}{*}{ Parameter } & \multicolumn{3}{c}{ Levels } \\
\cline { 3 - 5 } & & Low (-1) & Centre (0) & High (+1) \\
\hline $\mathrm{T}$ & Preheating temperature $\left({ }^{\circ} \mathrm{C}\right)$ & 450 & 500 & 550 \\
\hline $\mathrm{t}$ & Preheating time (hour) & 1 & 2 & 3 \\
\hline $\mathrm{VF}$ & Volume fraction of zirconium oxide $(\%)$ & 1 & 3 & 5 \\
\hline
\end{tabular}

In hot extrusion (the A process), the billet was preheated in a container with a ceramic heater to facilitate plastic deformation (Table 5) [13]. A graphite-based lubricant was used 
in the inner die surface and container in every extrusion cycle to prevent the increase in load in the extrusion due to friction [3].

Table 5. Factors used in conducting hot extrusion.

\begin{tabular}{cc}
\hline Parameter & Value/Type \\
\hline Shape of the die & Round \\
Ratio used in extrusion, $\mathrm{R}$ & 5.4 \\
Diameter of the billet, $\varnothing(\mathrm{mm})$ & 30 \\
Speed during extrusion, $\mathrm{s}(\mathrm{mm} / \mathrm{s})$ & 1 \\
Container temp, Tcont $\left({ }^{\circ} \mathrm{C}\right)$ & 300 \\
Die temp., Tdie $\left({ }^{\circ} \mathrm{C}\right)$ & 300 \\
\hline
\end{tabular}

After hot extrusion, the final products were divided into 28 specimens; then, the optimal properties were sample treated with hot ECAP (the B process) that used a cold press hydraulic machine of $500 \mathrm{kN}$, an ECAP die, heaters, and thermocouples, and the ECAP die consisted of two parts, with a channel of $12 \mathrm{~mm} \times 12 \mathrm{~mm}$ with an inner angle of $90^{\circ}$ and an outer angle of $20^{\circ}$. Temperatures were measured using a K-type thermocouple with a diameter of $3 \mathrm{~mm}$. Figure 3 shows the details of the setup.

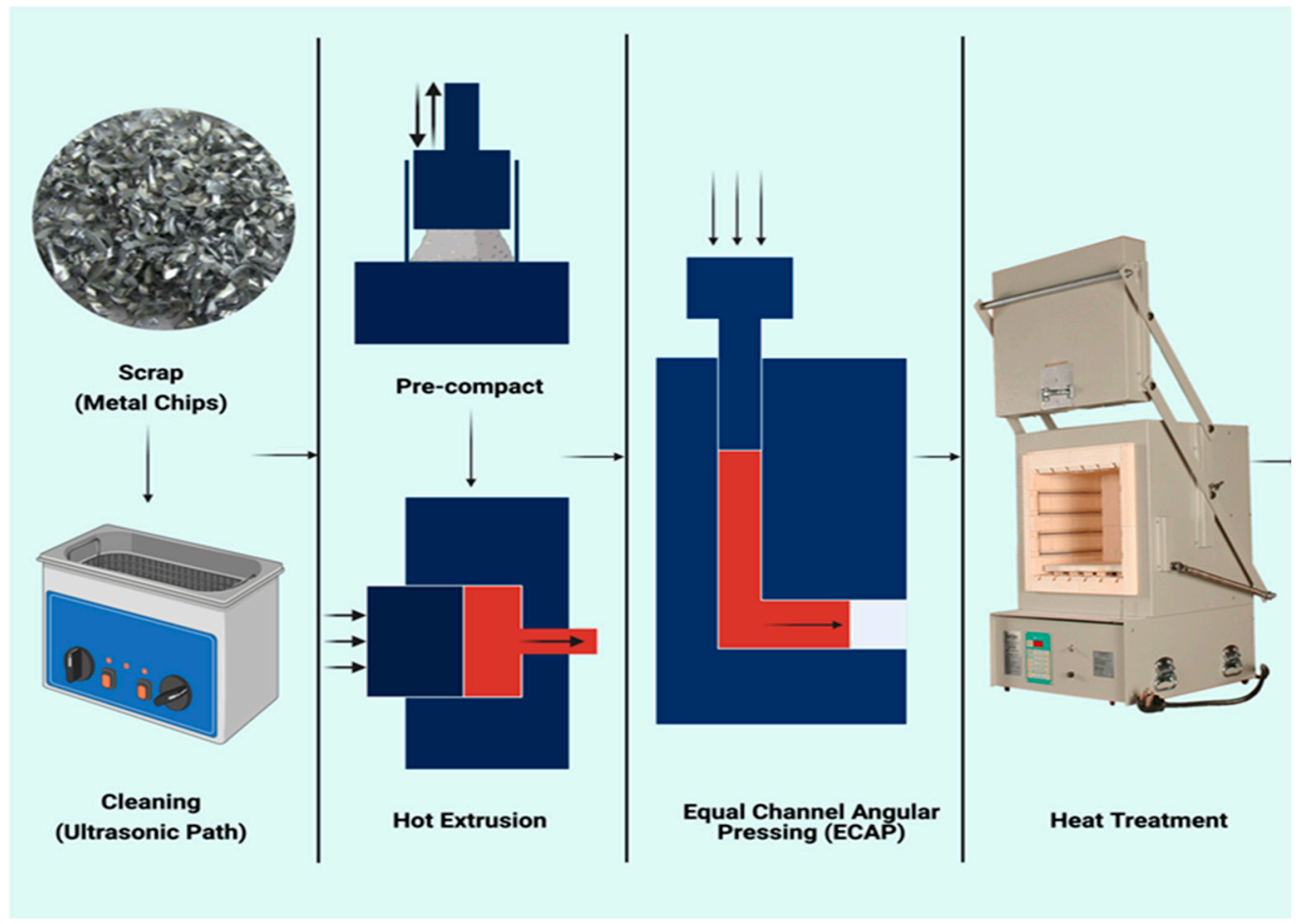

Figure 3. The sequence of the chip pre-processing before and after consolidation [14].

Heat treatment $(\mathrm{HT})$ was performed using an electrical box furnace at a quenching temperature of $465^{\circ} \mathrm{C}$ for $55 \mathrm{~min}$ and an artificial aging process at $120^{\circ} \mathrm{C}$ for $24 \mathrm{~h}$ (Figure 4). Water was used as the quenching medium.

The samples extruded from the hot extrusion die underwent tensile and microhardness tests. For tensile testing, the extruded samples were snipped according to the ASTM E8E8M standard for producing dog-bone-shaped samples. The tensile test with an initial strain rate of $2.53 \times 10^{-3} \mathrm{~s}^{-1}$ was performed at room temperature until failure. Based on the ASTM E92-82 standards, the microhardness test was performed using a Micro Vikers Hardness tester (Shimadzu) with a Knoop indenter, $25 \mathrm{~g}$ load (0.9807 N), indent time of $15 \mathrm{~s}$, and a holding time of $10 \mathrm{~s}$ at room temperature following the grinding of the surfaces for each sample for a balanced indentation. Samples were tested using a 
square-based, pyramid-shaped diamond indenter, indenting the samples in three places (top, centre, and bottom). These three values were averaged to yield the hardness for each sample. Microhardness was dependent on the plasticity, elasticity, strength, and ductility of the samples.

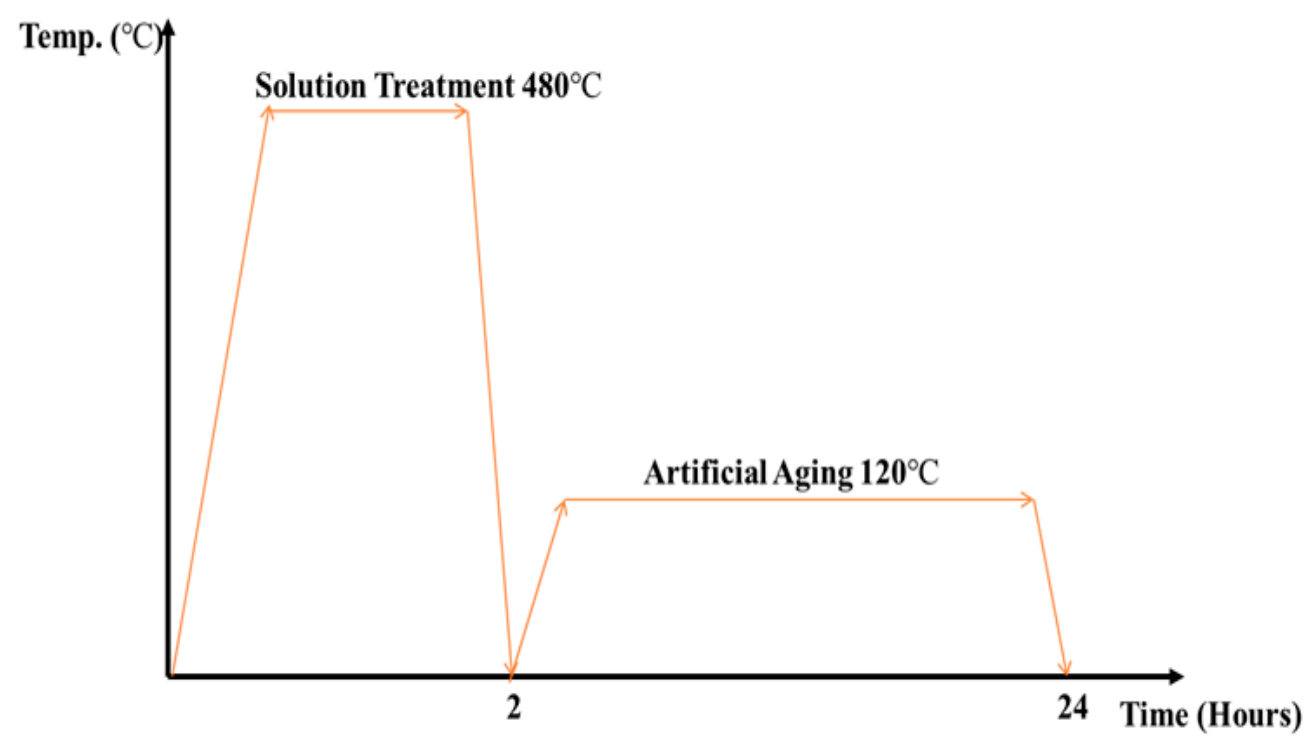

Figure 4. Heat treatment process.

The reinforced particles distribution, chip boundaries, and the grain size of the samples were evaluated using atomic force microscopy (AFM) and Scanning Electron Microscopy (SEM). Specifically, AFM was used to test the conductive materials by investigating the roughness of surface topography from the micro- to nanoscales of the prepared samples [15].The morphology of $\mathrm{ZrO}_{2}$ (shape and size) was evaluated using Field Emission Scanning Electron Microscopy with Energy Dispersive X-Ray Spectroscopy (FESEM-EDX) in three magnifications, i.e., $100 \times, 300 \times$, and $500 \times$. Meanwhile, the density was evaluated using Archimedes' water immersion principle with samples in circular pieces of approximately $1 \mathrm{~mm}$ in diameter and thickness and with the help of the HR-250AZ-Compact Analytical Balance density determination kit. Specimens were weighed in the air and distilled water to record the weight in different environments. Each sample was immersed in distilled water during the density measurement at room temperature. The density of the composite material was calculated using Equation (2) below [16].

$$
\text { Bulk density, } \rho_{\mathrm{b}}=\frac{A}{|B|} \times \text { density of distilled water }
$$

where $A=$ weight in the air and $B=$ weight in liquid. The difference of theoretical and measured density values gave the percentage of pores.

\section{Results and Discussion}

\subsection{Tensile Strength}

The tensile strength of the $\mathrm{Al}$ chips and $\mathrm{Al}-\mathrm{ZrO}_{2}$ composites produced from hot extrusion was congruent with the original material of T6-AA7075 containing $1 \% \mathrm{ZrO}_{2}$ nanoparticles and a preheating temperature of $550{ }^{\circ} \mathrm{C}$. Figure 5 shows the ultimate tensile strength (UTS) of the extruded samples due to work hardening. The tensile strength values were $583 \mathrm{MPa}$ for the sample AA7075 as received (AR), $470 \mathrm{MPa}$ for the sample after hot extrusion with $0.8 \% \mathrm{ZrO}_{2}$, and $631 \mathrm{MPa}$ after heat treatment. The extrusion encompassed the recycled $\mathrm{Al}$ chips and $\mathrm{Al}-1 \mathrm{vol} \% \mathrm{ZrO}_{2}$ composites with a tensile strength of $424 \mathrm{MPa}$ and $487 \mathrm{MPa}$, respectively, showing an enhancement in the mechanical properties of MMC. The tensile strength of $\mathrm{Al}-\mathrm{ZrO}_{2}$ was enhanced with the addition of nanoparticles until 
$1 \mathrm{vol} \%$, after which it decreased with the increment of nanopowder and optimised processing parameters for hot extrusion. The strength of the recycled MMC-based composites increased due to work hardening. These results showed a substantial increase in properties in heat-treated samples.

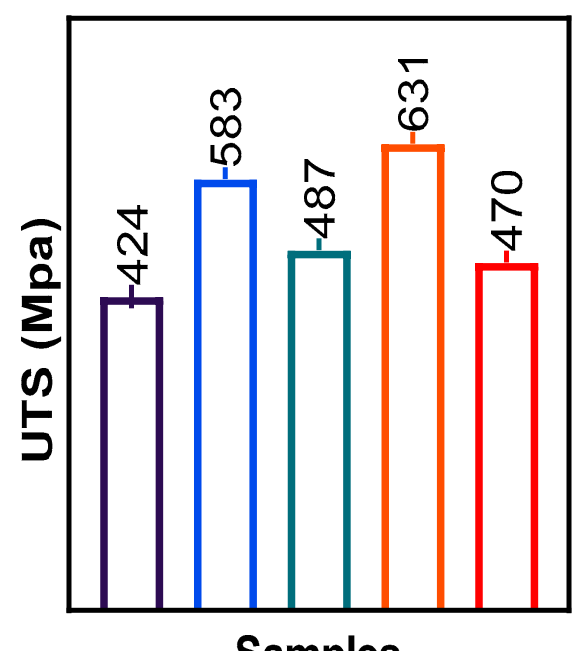

口 AA7075 Chips

口 AA7075 AR

口 AA7075 / 1 vol\%ZrO/A

$\square$ AA7075/ 1 vol\%ZrO/AHT

口 AA7075/ 0.8 vol\%ZrO/A

\section{Samples}

Figure 5. UTS of various composite samples.

The results suggest that specimens heated to the maximum temperature may have greater tensile strength. As the temperature rises, AMC becomes stronger and exposes the enhanced microstructure. By increasing the temperature to $550{ }^{\circ} \mathrm{C}$ and reducing the volume fraction to $1 \%$, the tensile strength is increased to its maximum value. According to RSM's explanation, it is obvious that the key parameter list that affects the investigation factors of the UTS of the extruded sample is $\mathrm{T}$ and $\mathrm{ZrO}_{2}$. On the contrary, time is not significant. SEM shows the sources of variance in Table 6, showing the $p$-value of the linear model. Temperature and reinforcement are significant, but the lack of fit is not significant. In the factor list, these factors are represented by $p<0.05$, as shown in the Pareto charts shown in Figure 6.

Table 6. The analysis of variance of UTS by RSM.

\begin{tabular}{|c|c|c|c|c|c|c|}
\hline Source & DF & Adj SS & Adj MS & F-Value & $p$-Value & Effect \\
\hline Model & 10 & $20,745.4$ & 2074.54 & 29.74 & 0.000 & Significant \\
\hline Blocks & 1 & 22.1 & 22.08 & 0.32 & 0.581 & \\
\hline Linear & 3 & 8308.4 & 2769.47 & 39.70 & 0.000 & Significant \\
\hline Temp. $\left({ }^{\circ} \mathrm{C}\right)$ & 1 & 5307.2 & 5307.25 & 76.08 & 0.000 & Significant \\
\hline Time (hour) & 1 & 91.1 & 91.08 & 1.31 & 0.269 & Not significant \\
\hline $\mathrm{ZrO}(\mathrm{Vol} \%)$ & 1 & 2910.1 & 2910.08 & 41.72 & 0.000 & Significant \\
\hline Square & 3 & 3098.9 & 1032.95 & 14.81 & 0.000 & Significant \\
\hline Temp. $\left({ }^{\circ} \mathrm{C}\right) \times$ Temp. $\left({ }^{\circ} \mathrm{C}\right)$ & 1 & 4.0 & 4.02 & 0.06 & 0.813 & \\
\hline Time (hour) $\times$ Time (hour) & 1 & 67.1 & 67.15 & 0.96 & 0.340 & \\
\hline $\mathrm{ZrO}(\mathrm{Vol} \%) \times \mathrm{ZrO}(\mathrm{Vol} \%)$ & 1 & 2278.2 & 2278.17 & 32.66 & 0.000 & \\
\hline 2-Way Interaction & 3 & 8281.5 & 2760.49 & 39.57 & 0.000 & Significant \\
\hline Temp. $\left({ }^{\circ} \mathrm{C}\right) \times$ Time (hour) & 1 & 67.4 & 67.45 & 0.97 & 0.339 & \\
\hline Temp. $\left({ }^{\circ} \mathrm{C}\right) \times \mathrm{ZrO}(\mathrm{Vol} \%)$ & 1 & 5184.4 & 5184.36 & 74.32 & 0.000 & \\
\hline Time (hour) $\times \mathrm{ZrO}(\mathrm{Vol} \%)$ & 1 & 3029.7 & 3029.68 & 43.43 & 0.000 & \\
\hline Error & 17 & 1185.8 & 69.75 & & & \\
\hline Lack-of-Fit & 5 & 417.8 & 83.57 & 1.31 & 0.325 & Not significant \\
\hline Pure Error & 12 & 768.0 & 64.00 & & & \\
\hline Total & 27 & $21,931.2$ & & & & \\
\hline
\end{tabular}




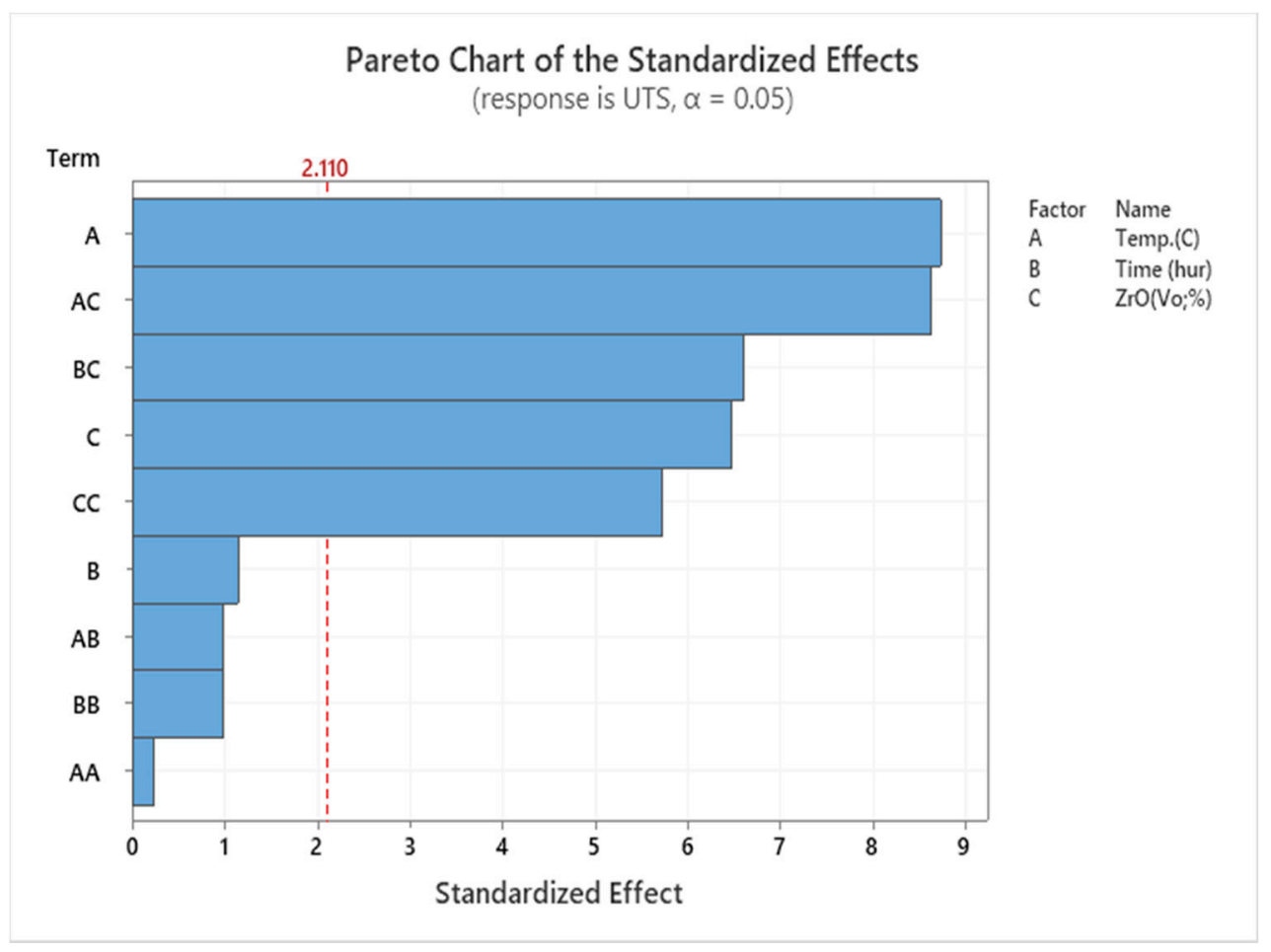

Figure 6. Pareto chart for UTS.

The coefficient of determination, $R^{2}$, adjusted $R^{2}$ and predicted $R^{2}$ are other criteria used to evaluate the adequacy of the model. For UTS, the value of $R^{2}, R^{2}$-adjusted and $\mathrm{R}^{2}$-predicted are $94.59 \%, 91.41 \%$, and $85.27 \%$, respectively. The value of $\mathrm{R}^{2}$ indicates that about $5 \%$ of the total variation was not explained by the model. This implies that the regression model provides an excellent explanation of the relationship between the independent variables and the response. By implication, the regression model is good and supports the experimental observations. Therefore, the result proves that the zirconium oxide nanoparticles added into the recycled AA7075 chips enhance the tensile stress of the newly developed composite material.

Specimens heated to the maximum temperature appeared to have greater tensile strength. As the temperature rose, aluminium matrix composite (AMC) became stronger and exposed the enhanced microstructure. Figure 5 shows that at $550{ }^{\circ} \mathrm{C}$ with the volume fraction reduced to $1 \%$, the tensile strength attained its maximum value, i.e., $487 \mathrm{MPa}$. Additionally, the samples extruded at $450{ }^{\circ} \mathrm{C}$ with a $5 \% \mathrm{ZrO}_{2}$ volume fraction showed poor strength (426 MPa). These results were consistent with that of another study [13]. Figure 7 shows the main effect plot in the full factorial analysis, indicating that all the centre points, from low to high preheating temperature settings, were extremely close to the straight line of the average tensile strength. Preheating temperature $(\mathrm{T})$ as a factor had a linear relationship to the UTS response. The tensile stress tended to decrease considerably with the increase in zirconium oxide up to $3 \%$ vol, where it started rise. Thus, the maximum UTS was obtained at the peak temperature at $550{ }^{\circ} \mathrm{C}$ and volume fraction at $1 \%$, as shown in the interaction plots in Figure 8. 


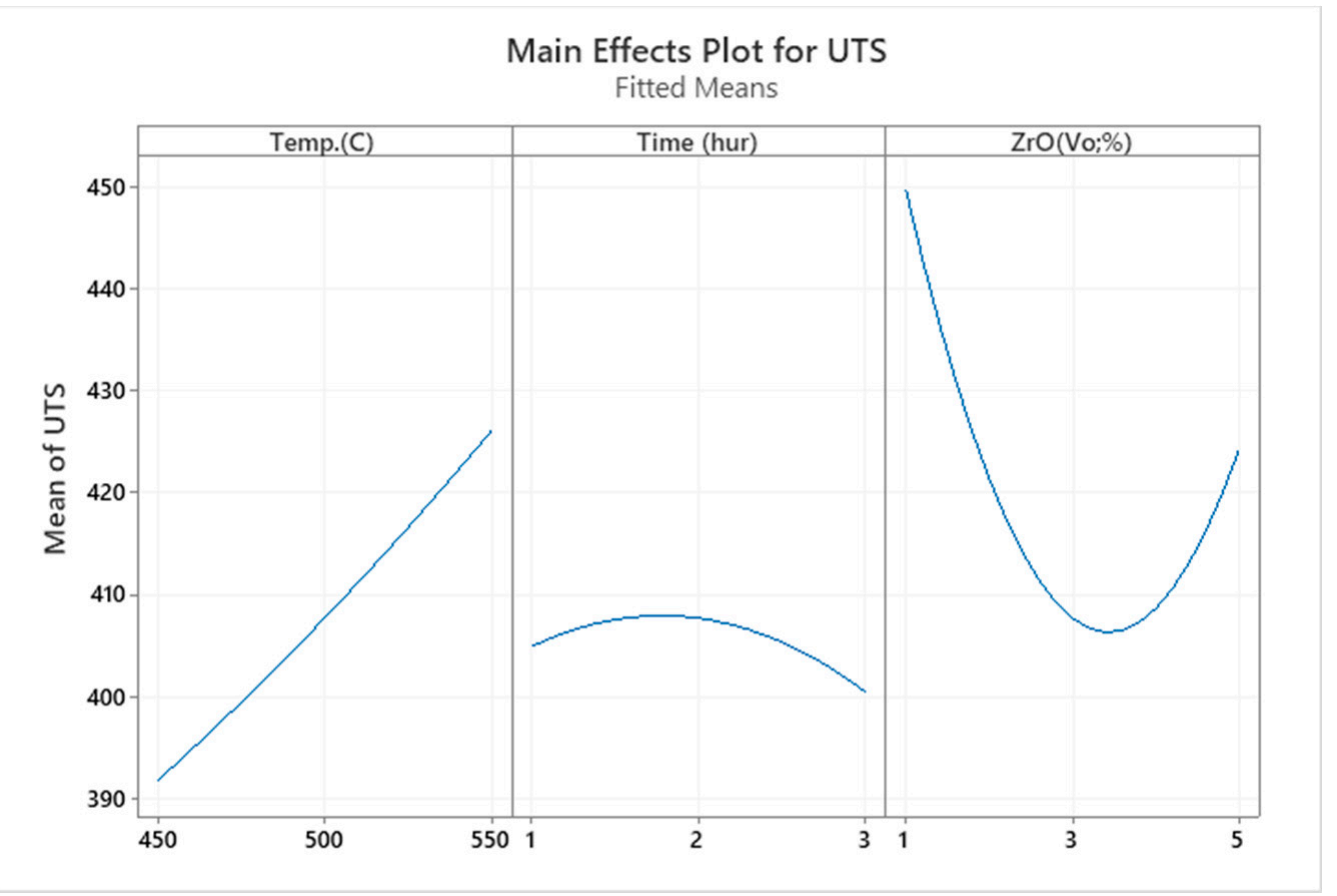

Figure 7. The main effect plot for UTS.

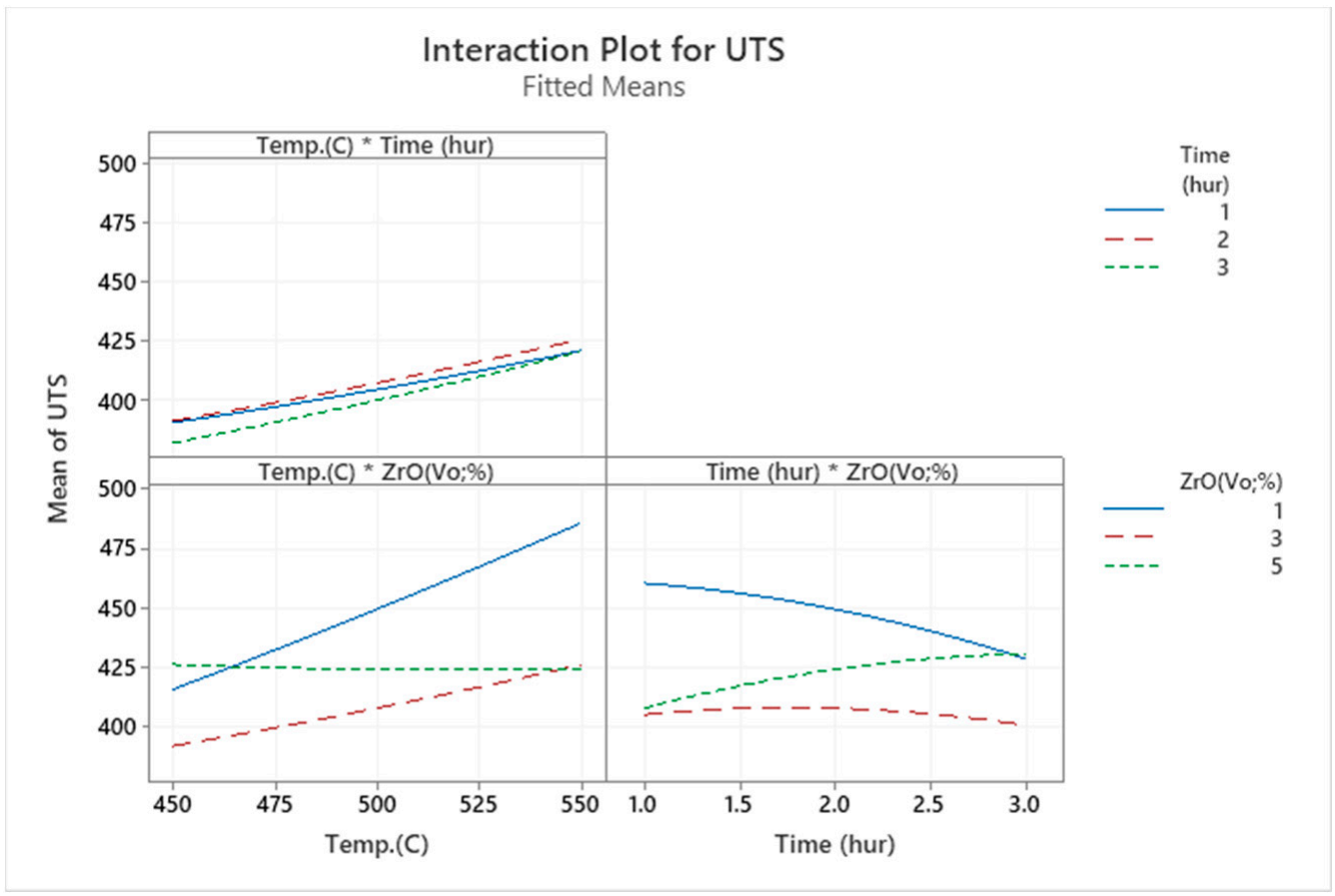

Figure 8. The interaction plot for UTS.

Figure 9 shows the residual plot for tensile strength. It is observed that the residual for UTS almost displays curvature in the normal probability plot. The closeness of the graph indicates that errors are negligible since they are in the tolerable margin. 


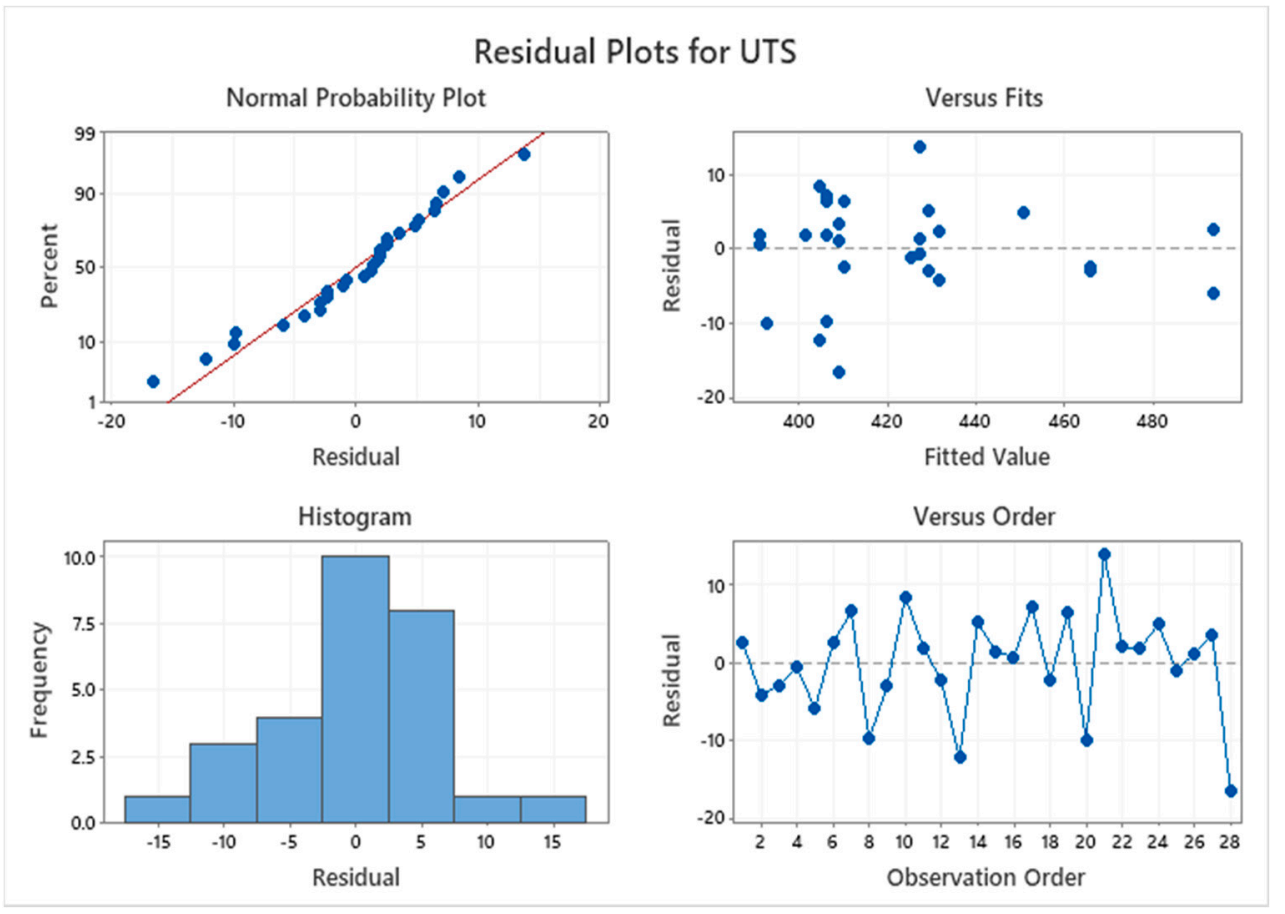

Figure 9. The residual plot for UTS.

\subsection{Effects of $\mathrm{ZrO}_{2}$ Nanoparticles on Microhardness}

Figure 10 shows the hardness of samples and Figure 11 shows the Pareto chart of the standardised effects. Regarding the hot extruded sample, the hardness (95 HV) was attained at $550{ }^{\circ} \mathrm{C}, 1 \mathrm{~h}$, and $1 \%$ for $\mathrm{T}$, t, and VF had increased to $135 \mathrm{HV}$ after the heat treatment. Subsequent ECAP reduced the microhardness to $100 \mathrm{HV}$, but it increased again to $140 \mathrm{HV}$ with further heat treatment.

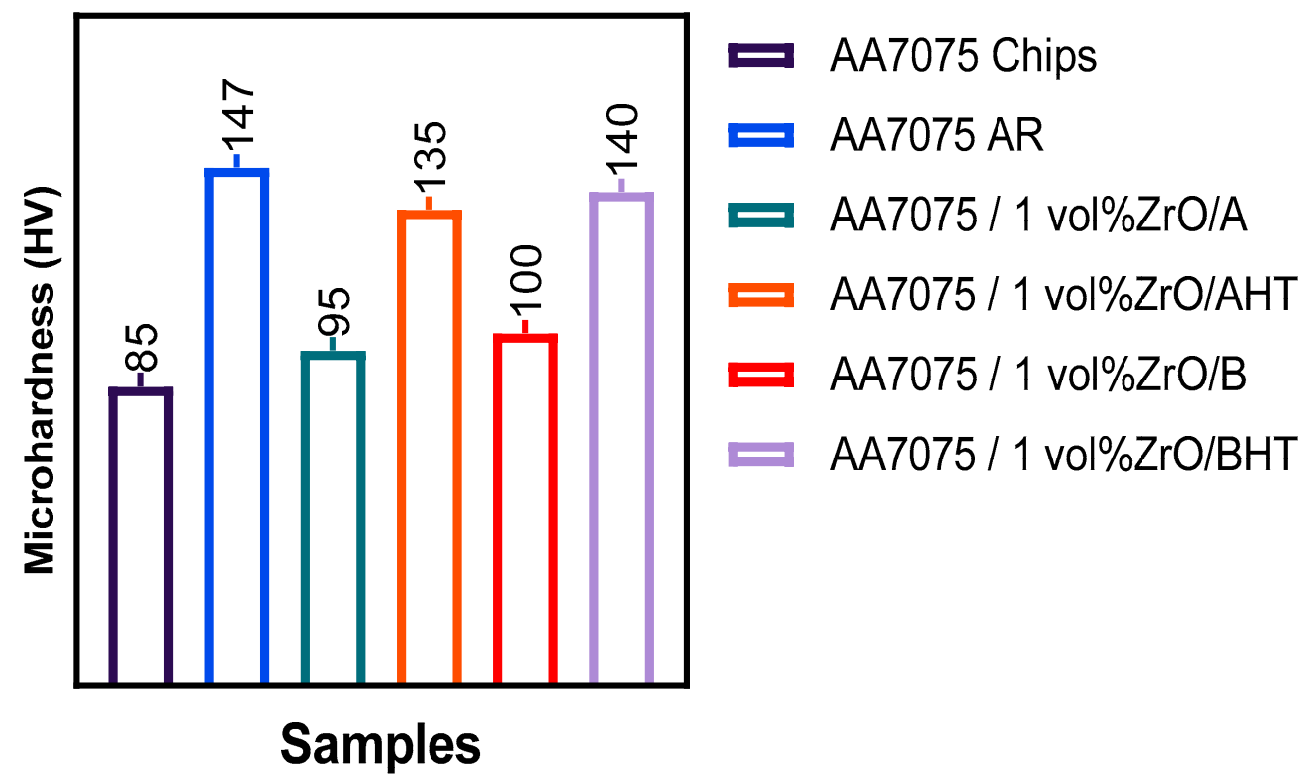

Figure 10. The hardness of the samples. 


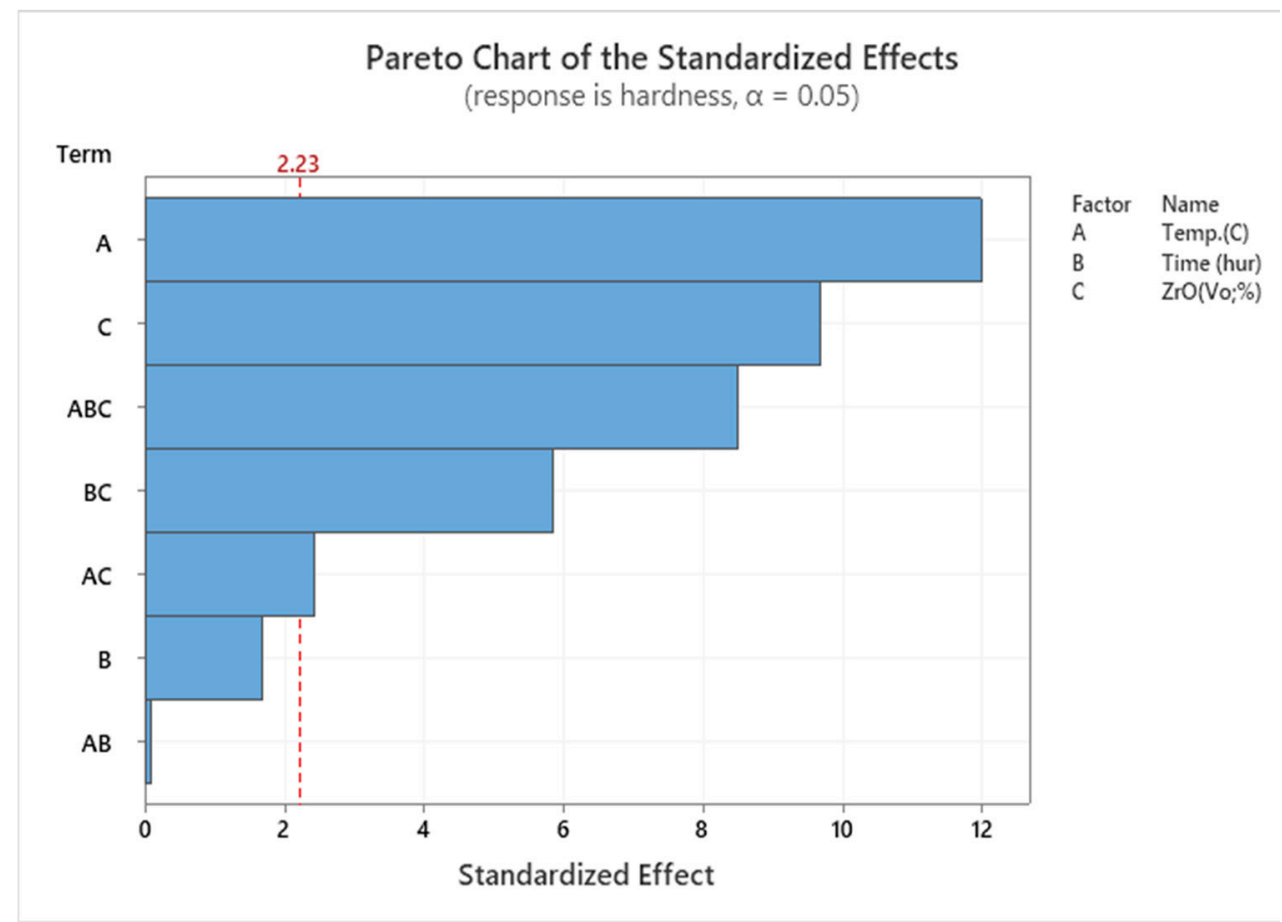

Figure 11. Pareto chart for hardness.

The full factorial results in Table 7 show that the model is significant. The $p$-value for the model is lower than 0.05 (i.e., $\alpha=0.05$, or $95 \%$ confidence). This indicates that the model is considered to be statistically significant. The curvature value is 0.18 , more than 0.05 , which means that is insignificant as desired; hence, the model fits the experimental data and the independent variables have considerable effects on the responses.

Table 7. The analysis of variance of hardness by full factorial.

\begin{tabular}{|c|c|c|c|c|c|c|}
\hline Source & DF & Adj SS & Adj MS & F-Value & $p$-Value & Effect \\
\hline Model & 8 & 1418.66 & 177.333 & 44.24 & 0.000 & Significant \\
\hline Linear & 3 & 961.29 & 320.429 & 79.95 & 0.000 & Significant \\
\hline Temp. $\left({ }^{\circ} \mathrm{C}\right)$ & 1 & 574.79 & 574.791 & 143.41 & 0.000 & Significant \\
\hline Time (hour) & 1 & 11.37 & 11.370 & 2.84 & 0.123 & Not significant \\
\hline $\mathrm{ZrO}(\mathrm{Vol} \%)$ & 1 & 375.13 & 375.127 & 93.59 & 0.000 & Significant \\
\hline 2-Way Interactions & 3 & 160.75 & 53.583 & 13.37 & 0.001 & Significant \\
\hline Temp. $\left({ }^{\circ} \mathrm{C}\right) \times$ Time (hour) & 1 & 0.04 & 0.042 & 0.01 & 0.921 & \\
\hline Temp. $\left({ }^{\circ} \mathrm{C}\right) \times \mathrm{ZrO}(\mathrm{Vol} \%)$ & 1 & 23.61 & 23.606 & 5.89 & 0.036 & \\
\hline Time (hour) $\times \mathrm{ZrO}(\mathrm{Vol} \%)$ & 1 & 137.10 & 137.100 & 34.21 & 0.000 & \\
\hline 3-Way Interactions & 1 & 288.29 & 288.293 & 71.93 & 0.000 & Significant \\
\hline Temp. $\left({ }^{\circ} \mathrm{C}\right) \times$ Time (hour) $\times \mathrm{ZrO}(\mathrm{Vol} \%)$ & 1 & 288.29 & 288.293 & 71.93 & 0.000 & \\
\hline Curvature & 1 & 8.33 & 8.332 & 2.08 & 0.180 & Not significant \\
\hline Error & 10 & 40.08 & 4.008 & & & \\
\hline Total & 18 & 1458.74 & & & & \\
\hline
\end{tabular}

For microhardness, the value of $\mathrm{R}^{2}, \mathrm{R}^{2}$-adjusted and $\mathrm{R}^{2}$-predicted are $97.25 \%, 95.05 \%$, and $90 \%$, respectively. The value of $\mathrm{R}^{2}$ indicates that less than $3 \%$ of the total variation was not explained by the model. This means that the regression model provides an excellent explanation of the relationship between the independent variables and the response. The

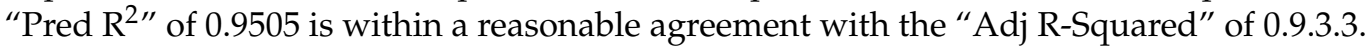

The full factorial conducted for density test (Figure 12) shows the density of the samples. The RSM analysis indicated that the density increased along all the parameters used in sample extrusion. The maximum density $\left(2.89 \mathrm{~g} / \mathrm{cm}^{3}\right)$ was attained at $450{ }^{\circ} \mathrm{C}$, 
$3 \mathrm{~h}$, and $5 \%$ for $\mathrm{T}, \mathrm{t}$, and VF, respectively; for the ECAP sample, the maximum density $\left(2.89 \mathrm{~g} / \mathrm{cm}^{3}\right)$ was attained at $550{ }^{\circ} \dot{\mathrm{C}}, 1.58 \mathrm{~h}$, and $1 \%$ for T, t, and VF and $2.9 \mathrm{~g} / \mathrm{cm}^{3}$ after heat treatment, indicating that high temperature and dense compaction of the chips resulted in poor inter-chip consolidation [17]. These extrusion conditions were only suitable for eliminating the voids and were incapable of improving the chip bonding. Although samples extruded at high temperatures had higher strength [18], such conditions resulted in lower density due to the formation of residual voids and cracks in the extruded products. In general, the preheating temperature along with preheating time and volume fraction of $\mathrm{ZrO}_{2}$ were relatively more crucial for determining the density in the hot extrusion of the solid-state recycling method.

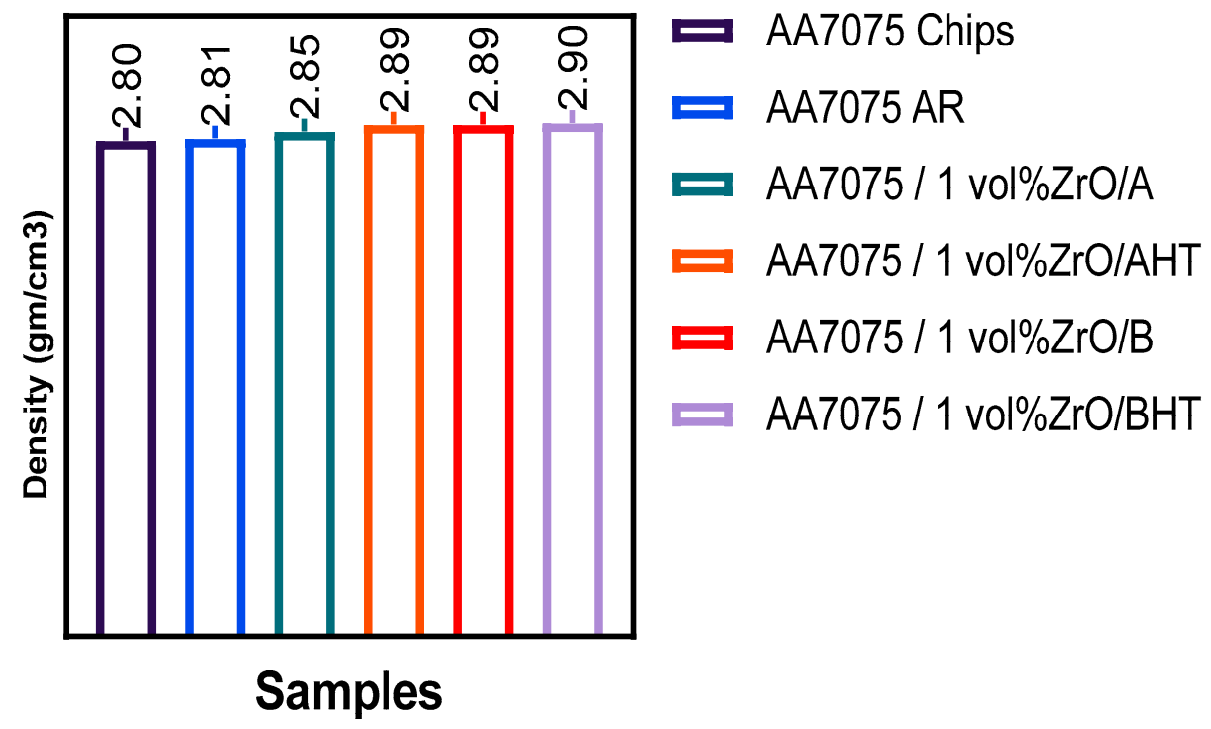

Figure 12. The results of density.

The factorial regression results in Table 8 show that the model is significant. The $p$-value for the model is lower than 0.05 (i.e., $\alpha=0.05$, or $95 \%$ confidence). This indicates that the model is considered to be statistically significant. The value of lack of fit term is 0.126 , more than 0.05 . The interpretation of this is that the model is significant, as desired. The model fit the experimental data and the independent variables have considerable effects on the response.

Table 8. The analysis of variance of density by full factorial.

\begin{tabular}{ccccccc}
\hline Source & DF & Adj SS & Adj MS & F-Value & $p$-Value & Effect \\
\hline Model & 6 & 0.027477 & 0.004580 & 169.94 & 0.000 & Significant \\
Linear & 3 & 0.017620 & 0.005873 & 217.95 & 0.000 & Significant \\
Temp. $\left({ }^{\circ} \mathrm{C}\right)$ & 1 & 0.007801 & 0.007801 & 289.50 & 0.000 & Significant \\
Time (hour) & 1 & 0.003156 & 0.003156 & 117.10 & 0.000 & Significant \\
ZrO (Vol\%) & 1 & 0.006663 & 0.006663 & 247.24 & 0.000 & Significant \\
2-Way Interactions & 2 & 0.008948 & 0.004474 & 166.02 & 0.000 & Significant \\
Temp. $\left({ }^{\circ} \mathrm{C}\right) \times$ Time (hour) & 1 & 0.000644 & 0.000644 & 23.89 & 0.000 & 0.000 \\
Temp. $\left({ }^{\circ} \mathrm{C}\right) \times$ ZrO (Vol\%) & 1 & 0.008304 & 0.008304 & 308.14 & & Significant \\
Error & 12 & 0.000323 & 0.000027 & & & Not significant \\
Lack-of-Fit & 2 & 0.000110 & 0.000055 & 2.57 & & \\
Pure Error & 10 & 0.000214 & 0.000021 & & &
\end{tabular}

The coefficient of determination for density, the value of $R^{2}, R^{2}$-adjusted, and $R^{2}$ predicted are $98.24 \%, 96.83 \%$, and $93.22 \%$, respectively. The value of $R^{2}$ indicates that only about $1 \%$ of the total variation was not explained by the model. This implies that 
the regression model provides an excellent explanation of the relationship between the independent variables and the response.

The results in Table 8, the Pareto chart (Figure 13), and the comparison of hardness, density, and UTS (Figure 14) clearly show these relationships.

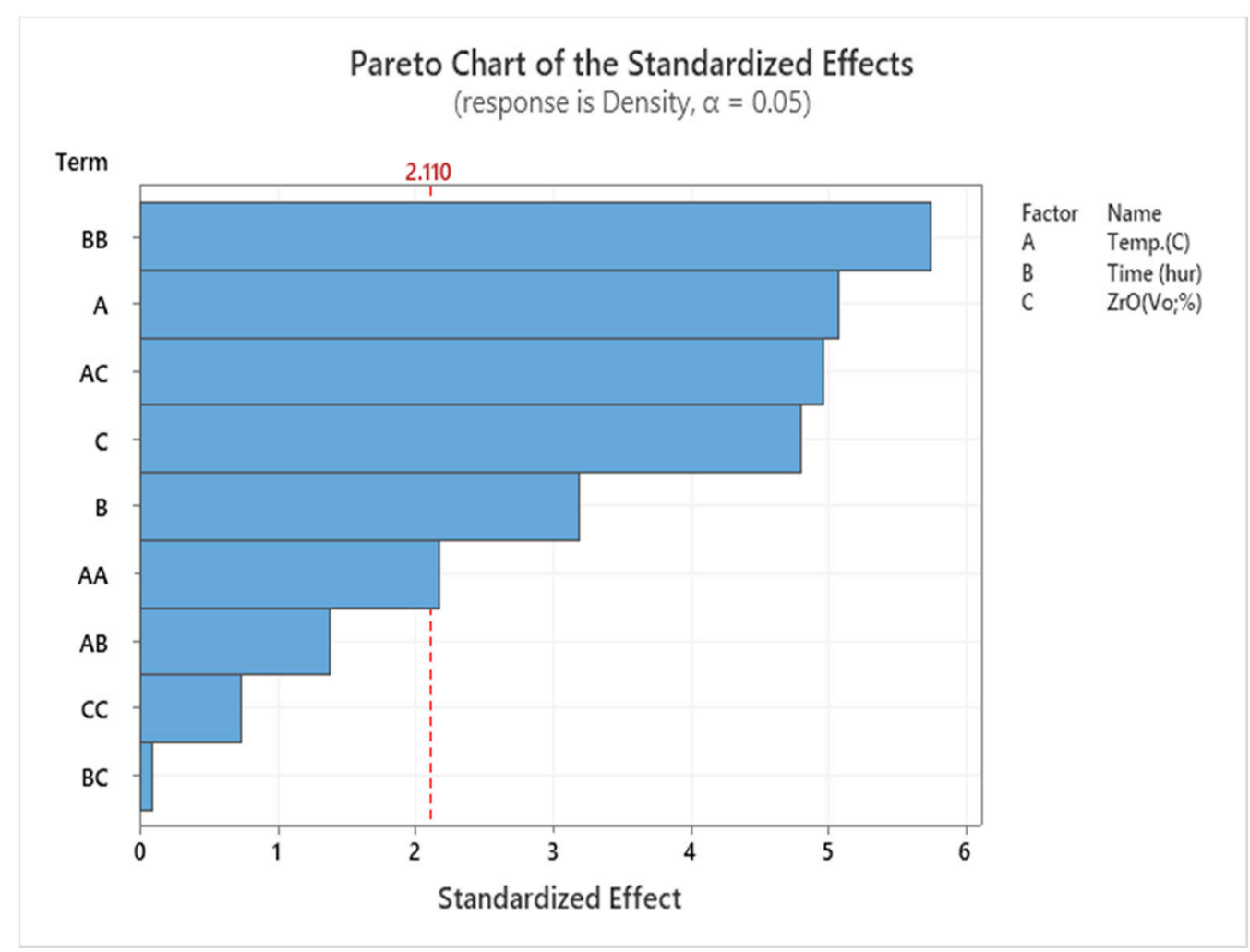

Figure 13. Pareto chart for density.

\subsection{Multi-Objective Optimisation}

The multi-objective optimisation results of this study were consistent with the above optimal results, especially with $\mathrm{T}$ and VF. The maximum responses of this study for $\mathrm{T}, \mathrm{t}$, and VF were $550{ }^{\circ} \mathrm{C}, 1.6 \mathrm{~h}$, and $1 \mathrm{vol} \% \mathrm{ZrO}_{2}$. The average UTS, microhardness, and density of this study were $490 \mathrm{MPa}, 95.2 \mathrm{HV}$, and $2.89 \mathrm{~g} / \mathrm{cm}^{3}$, respectively (Figure 14).

\subsection{Validation Test and Prediction}

The results of the experimental tensile strength, microhardness, and density tests for the three specimens are given in Table 9. Three confirmation tests (CTs) were performed to validate the empirical results. Based on the design of experiment (DOE) analysis, the model can be seen in this table; the calculated errors are within manageable limits and small compared to the obtained results. The calculated errors between the experimental and the predicted result (Table 10) are within the range of $0.1 \%$ to $10.0 \%$ or $\pm 10 \%$. Clearly, these results successfully confirm the reproducibility of the experimental data. 


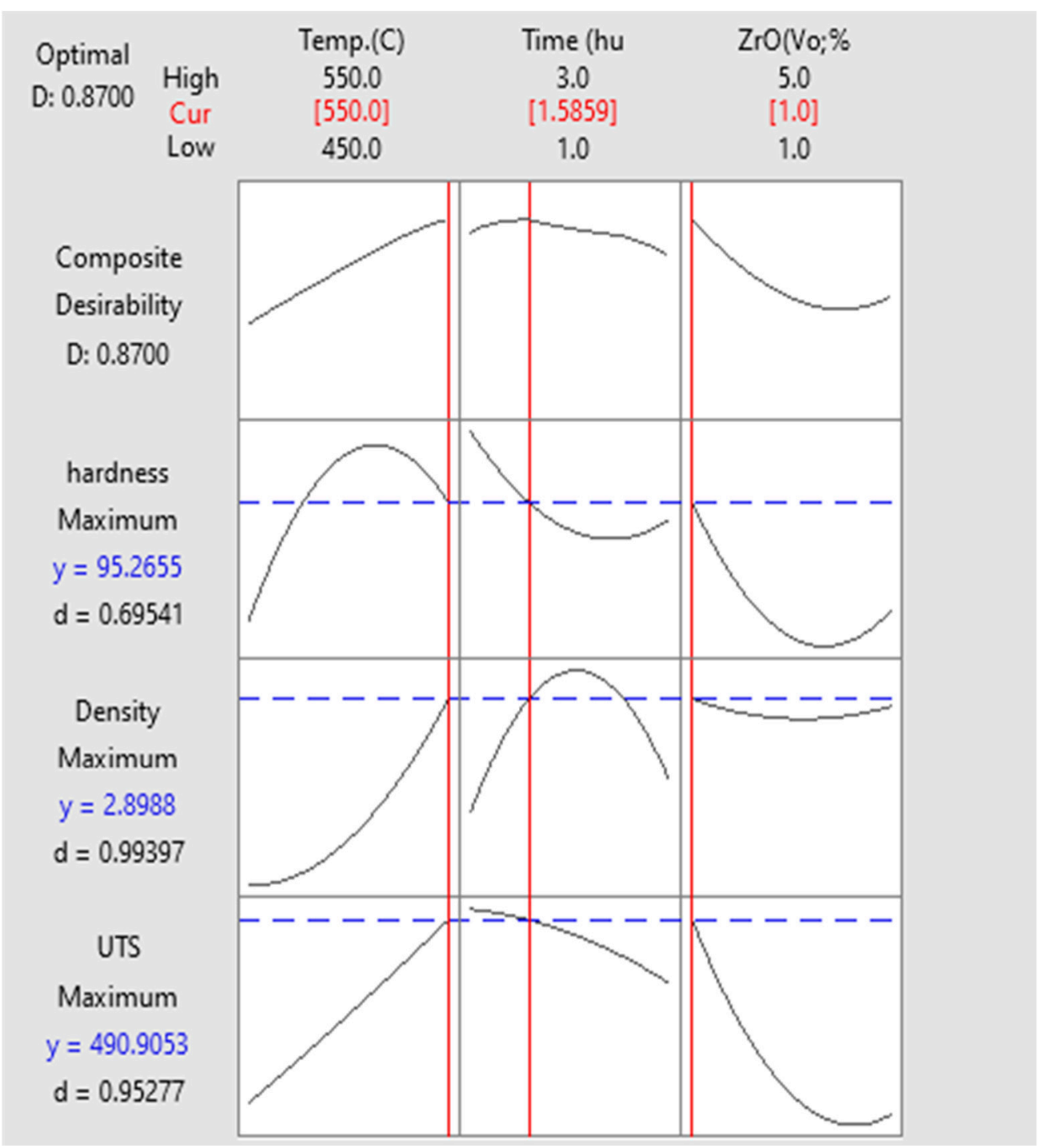

Figure 14. UTS, microhardness and density optimal plot.

Table 9. The confirmation test results.

\begin{tabular}{cccccccccc}
\hline \multirow{2}{*}{ CT } & \multirow{2}{*}{ Temp } & \multirow{2}{*}{ Time } & \multirow{2}{*}{$\mathrm{ZrO}_{2}$} & \multicolumn{3}{c}{ Experimental } & \multicolumn{3}{c}{ Predicted } \\
\cline { 5 - 9 } & & & & UTS & HardnessDensity & UTS & HardnessDensity \\
\hline 1 & 550 & 1.58 & 1 & 487.78 & 97 & 2.75 & 490.23 & 102.56 & 2.87 \\
2 & 542 & 1 & 1 & 489.88 & 103 & 2.8 & 488.55 & 102.42 & 2.86 \\
3 & 550 & 1.58 & 0.8 & 469 & 95.2 & 2.81 & 500.01 & 99.90 & 2.87 \\
\hline
\end{tabular}

Table 10. RSM prediction error.

\begin{tabular}{cccc}
\hline \multirow{2}{*}{ Prediction Error } & \multicolumn{3}{c}{ Error \% } \\
\cline { 2 - 4 } & UTS & Hardness & Density \\
\hline CT 1 & 0.50 & 5.73 & 4.44 \\
CT 2 & 0.27 & 0.57 & 2.12 \\
CT 3 & 6.61 & 4.94 & 2.22 \\
\hline
\end{tabular}

\subsection{Scanning Electron Microscopy (SEM) Analysis}

Surface fracture of the $\mathrm{ZrO}_{2}$ nanoparticles and the damage mechanism for the AA7075 extruded sample (Figure 15a), and the microstructure of the reinforced samples with $\mathrm{ZrO}_{2}$ 
nanoparticles (Figure 15b) with a uniform distribution of particles in the MMC are shown. The ceramic phase was dark, and the white one was the metal matrix of AA7075. The distribution of the composite was dependent on the good interfacial bonding between $\mathrm{ZrO}_{2}$ nanoparticles and the matrix along the grain boundaries that redacted the equiaxed dimples. However, microvoids were visible in some regions.

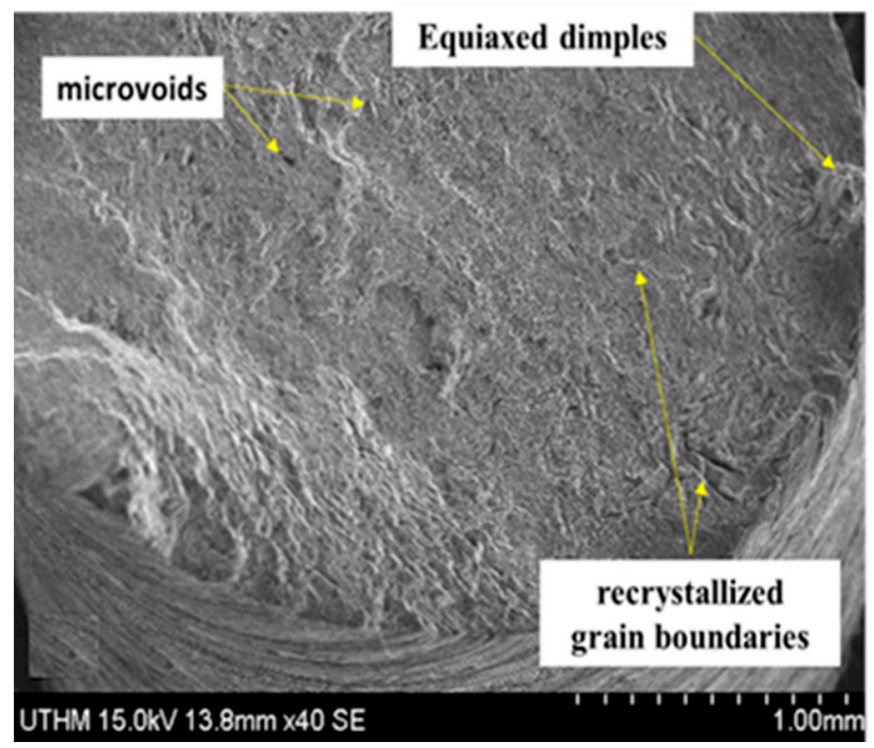

(a)

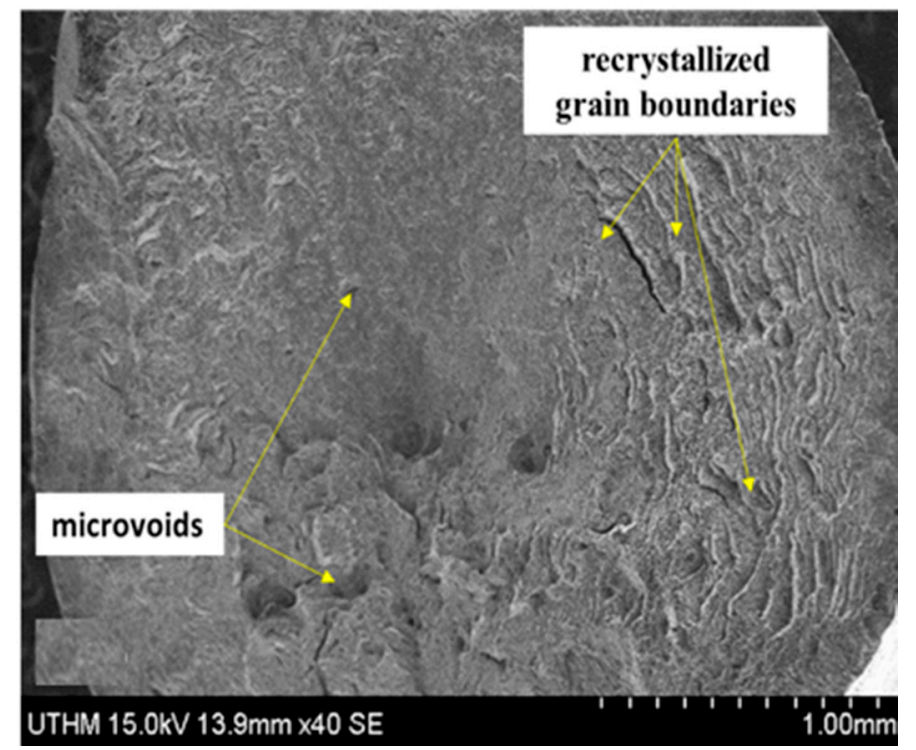

(b)

Figure 15. (a) AA7075 chips (b) $1 \mathrm{vol} \% \mathrm{ZrO}_{2} / \mathrm{A}$.

\subsection{Field Emission Scanning Electron Microscope (FESEM) Ultimate Tensile Strength Fracture Surface}

The FESEM analysis showed that hot extruded specimens exhibited no voids or cracks. The density test confirmed this FESEM finding; samples that underwent extrusion followed by heat treatment showed a density of $2.89 \mathrm{~g} / \mathrm{cm}^{3}$. This value was higher than that of the AR samples. The density test strongly indicated possible porosities and a strong correlation with the porosity of the material. In comparison, hot extruded samples had less particle agglomeration and smaller grain sizes in the AFM sample profile (Table 11). Grain sizes were congruent with the results of AR AA7075. Figure 16 shows the boundaries of hot extruded samples for the AR sample.

Table 11. AFM topography images of recycled samples.

Samples


Table 11. Cont.

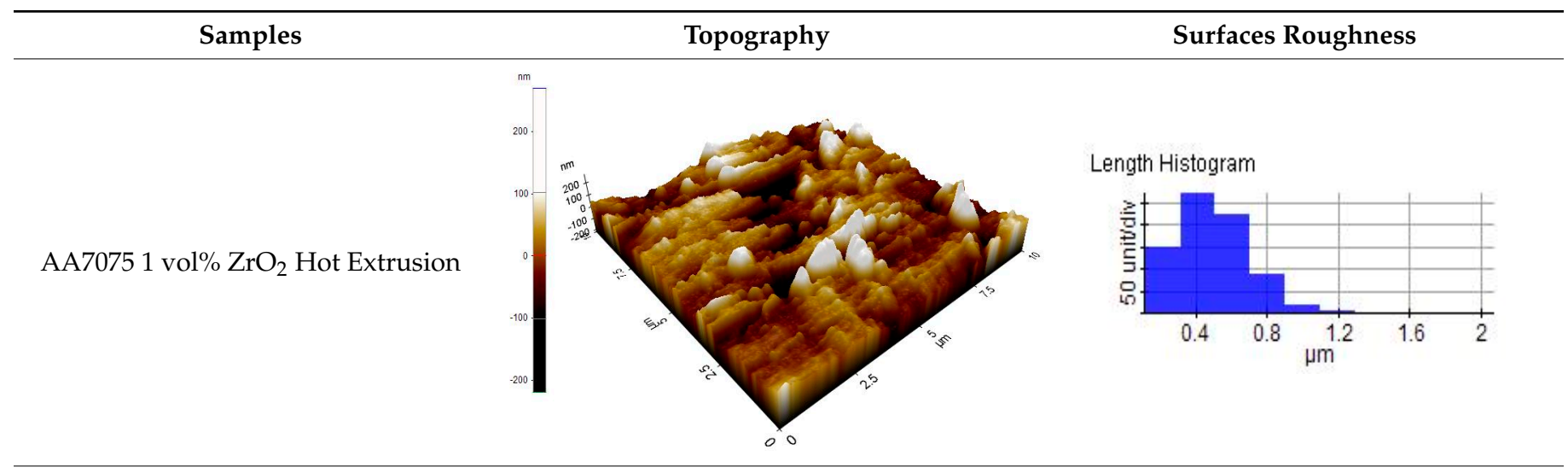

AA7075 1 vol $\% \mathrm{ZrO}_{2}$ Hot Extrusion/HT

AA7075 1 vol $\% \mathrm{ZrO}_{2}$ Hot Extrusion/ECAP

AA7075 1 vol $\% \mathrm{ZrO}_{2}$ Hot Extrusion/ECAP/HT

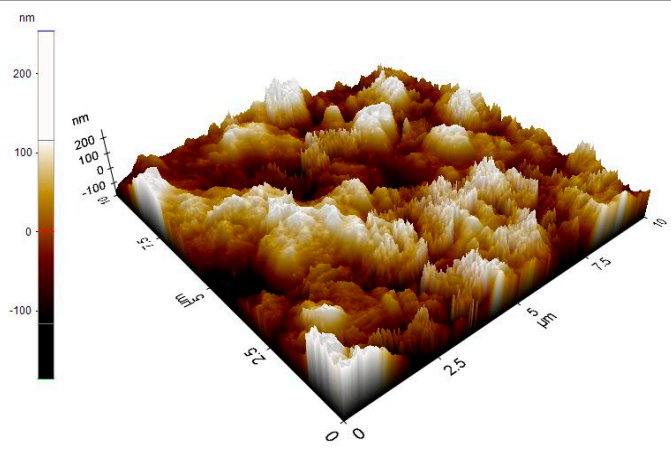

Length Histogram

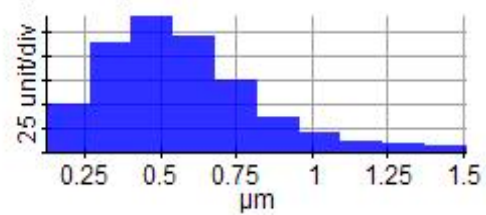

Length Histogram

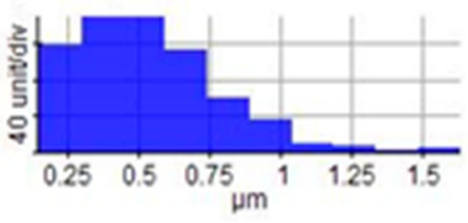

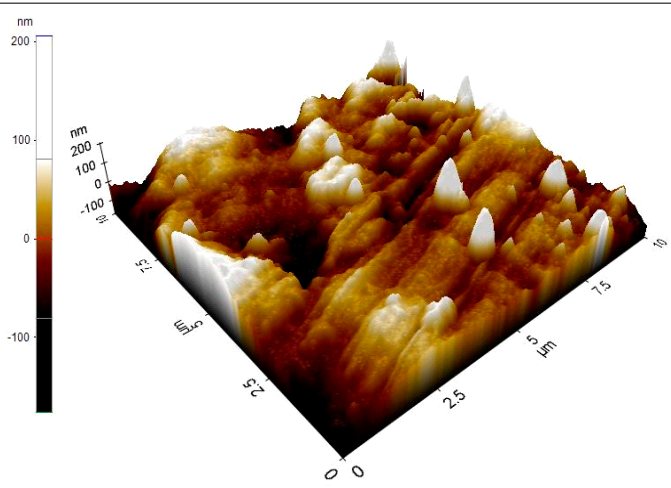

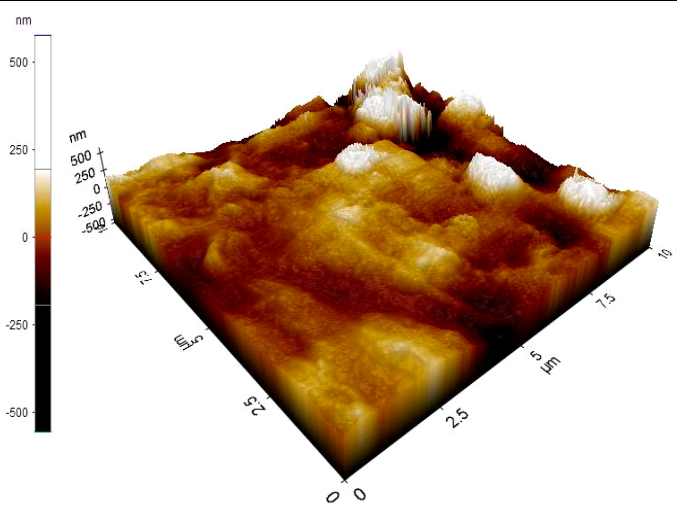

Length Histogram

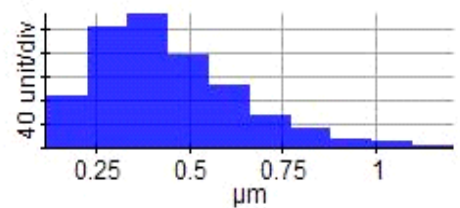



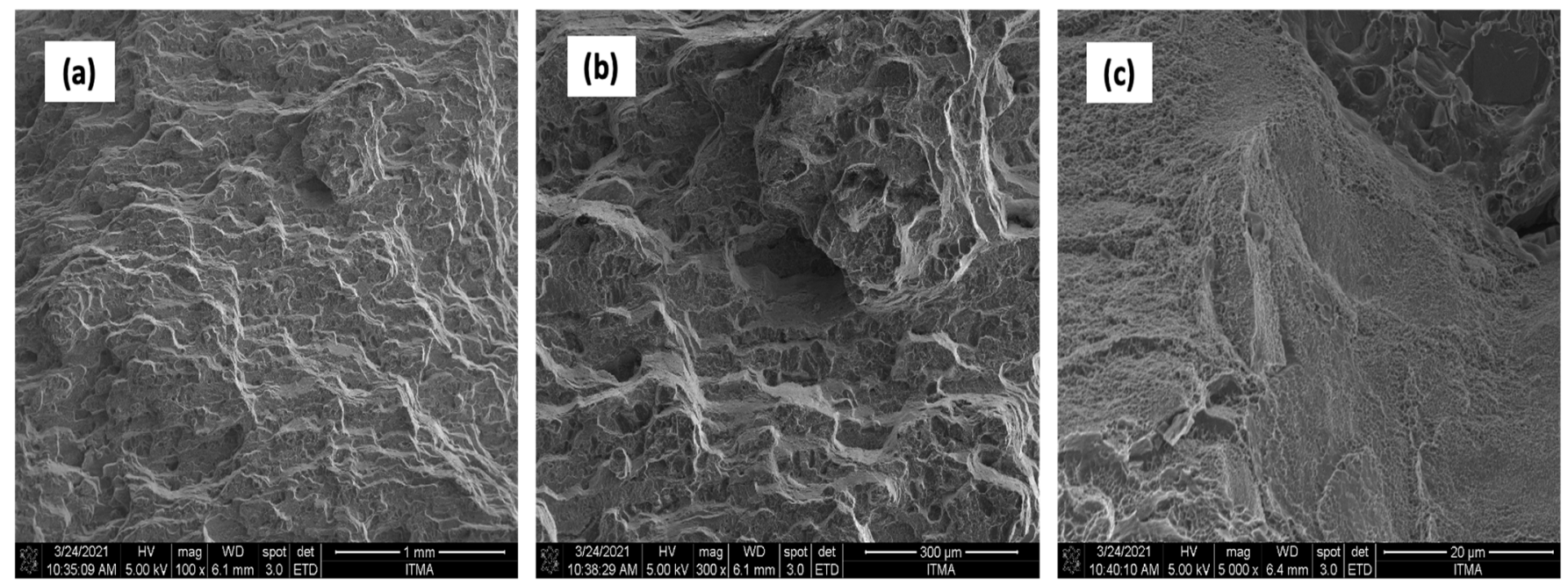

Figure 16. AA7075 AS (a) $100 \times$ (b) $300 \times$ (c) $5000 \times$.

Uniformly distributed dimples and small cracks could be seen on the surface of the sample AA7075 chips, as shown in Figure 17 . At $550^{\circ} \dot{\mathrm{C}}, 3 \mathrm{~h}$, clear tears and micro cracks were observed on the fracture.
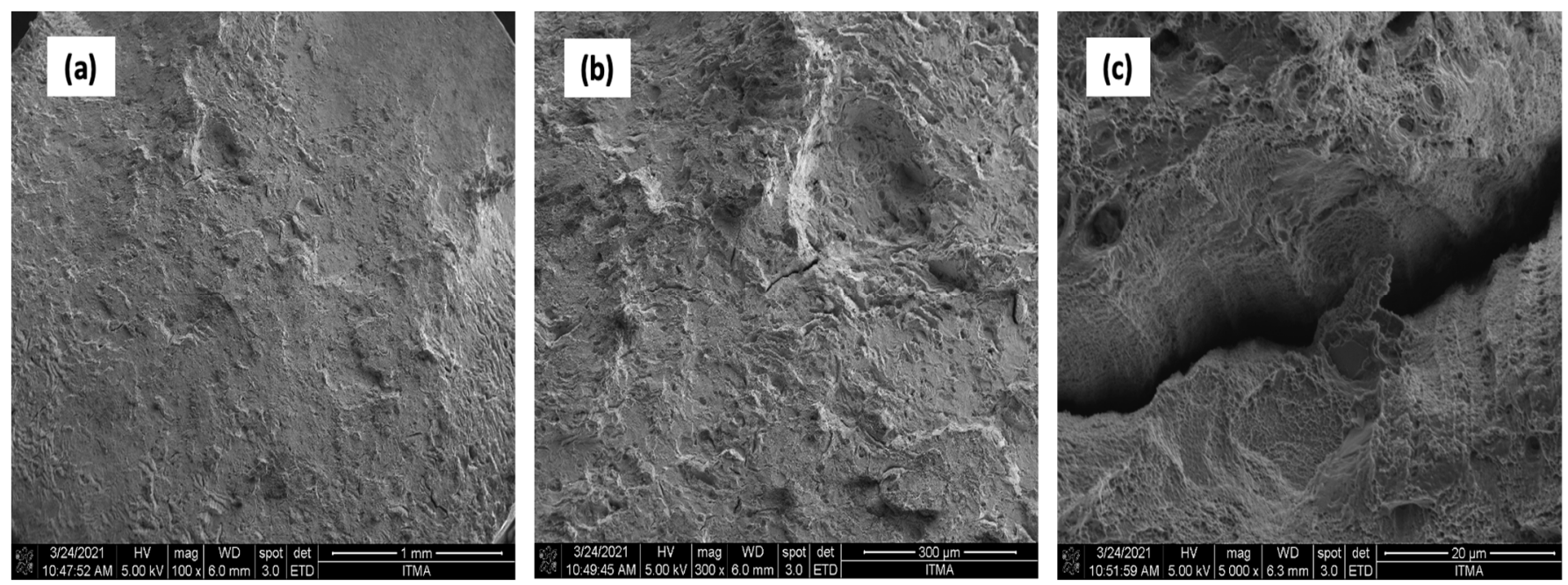

Figure 17. AA7075 chips (a) $100 \times$ (b) $300 \times$ (c) $5000 \times$.

Additionally, Figure 18 shows the presence of uniformly distributed dimples and small cracks on the fracture surface of the sample reinforced with $1 \mathrm{vol} \% \mathrm{ZrO}_{2}$. Tears and micro-cracks appeared at $550{ }^{\circ} \mathrm{C}$ and $3 \mathrm{~h}$, and cleavage planes decreased obviously. An outer topography was visible (Figure 18a). The poor bonding between the chips showed a ridge instead of equiaxed dimples. Voids and pores were seen on the chip boundaries that resulted in oxidation during the fabrication process.

UTS and microhardness were enhanced in heat treatment, leading to a lack of voids and cracks in the sample's microstructure. Figure 19 shows the microstructure of heattreated samples. Nanomaterial reinforcement reduced the cracks (Figure 19b) and hence, the ultimate tensile strength and microhardness. 

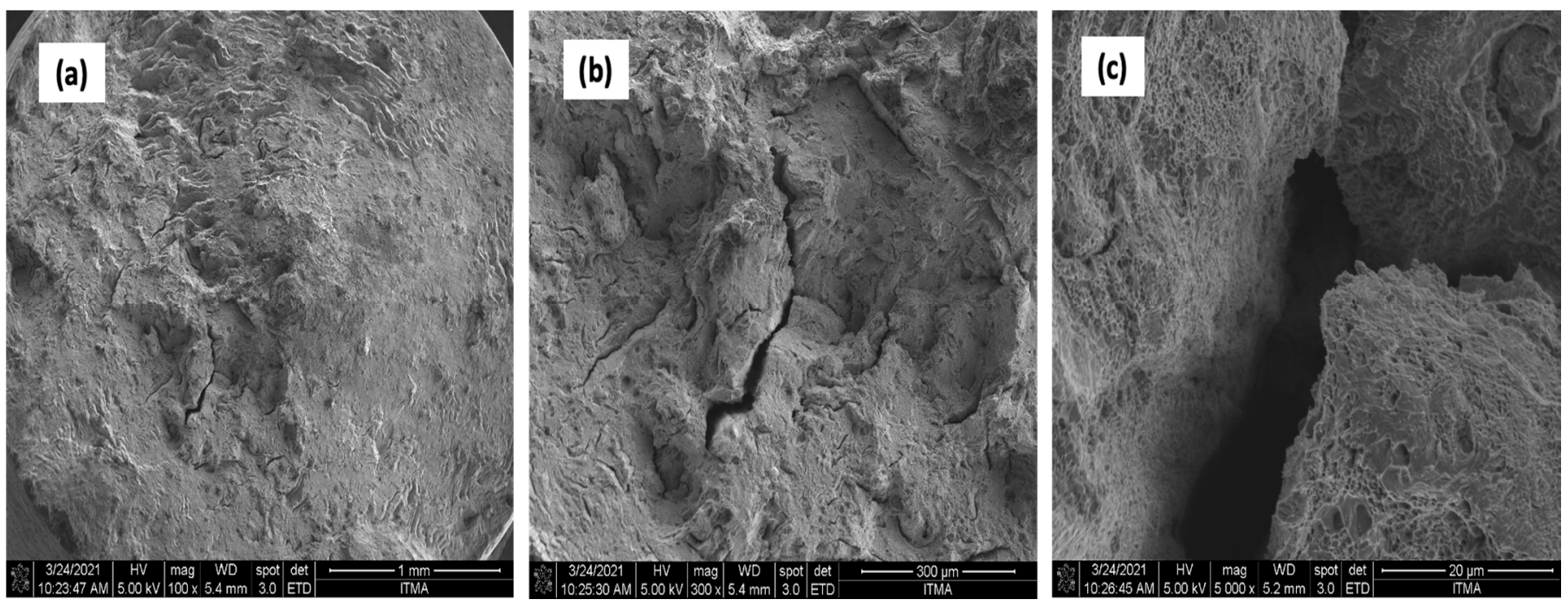

Figure 18. AA7075 1\% vol $\mathrm{ZrO}_{2}$ (a) $100 \times$ (b) $300 \times$ (c) $5000 \times$.
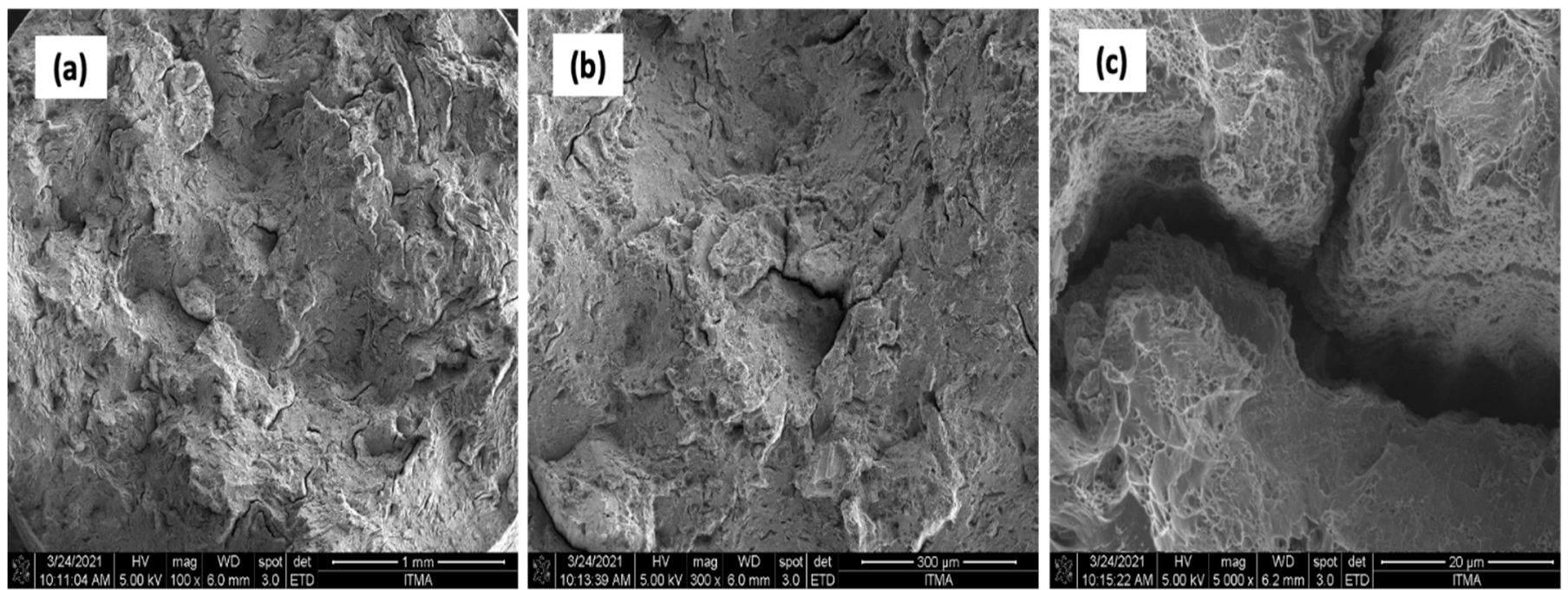

Figure 19. AA7075 1\% vol $\mathrm{ZrO}_{2} / \mathrm{HT}$ (a) $100 \times$ (b) $300 \times$ (c) $5000 \times$.

\subsection{Atomic Force Microscope Analysis (AFM)}

The microstructure was changed altered during the extrusion process, depending on the $\mathrm{ZrO}_{2}$ particle content in aluminium chips. The grains were less organised. When the volume fraction of particles was increased, the surface's appearance was significantly increased after the hot extrusion forming process. All of the obtained grains, polycrystalline, and structure appeared to depend on the materials' film thickness, and the lateral effective grains distributions are presented in Tables 11 and 12. The most presented lateral decreased scales in the film thickness are $0.49 \mu \mathrm{m}$ to $0.286 \mu \mathrm{m}$ after extrusion and from 0.488 to 0.433 after ECAP. The arithmetic roughness (Ra) for all samples decreased from 13.849, 9.879, and $16.279(\mathrm{~nm})$ of AA7075 chips, $1 \% \mathrm{vol}$ of $\mathrm{ZrO}_{2}$ before and after heat treatment, respectively. The root means square $(\mathrm{Rq})$ also was reported as $17.43 \mathrm{~nm}, 12.558 \mathrm{~nm}$, and $19.427 \mathrm{~nm}$ for AA7075 chips, $1 \%$ vol of $\mathrm{ZrO}_{2}$ produced by extrusion and $1 \%$ vol of $\mathrm{ZrO}_{2}$ produced by extrusion followed by ECAP, respectively. It was confirmed that the aluminium composite properties were enhanced, with the grain size reduction of the investigated samples being related to the increases in the time spent and its growth. 
Table 12. AFM mean grain size and surfaces roughness.

\begin{tabular}{|c|c|c|c|}
\hline Samples & Mean Grain Size $(\mu \mathrm{m})$ & $\operatorname{Ra}(\mathbf{n m})$ & $\mathbf{R q}(\mathbf{n m})$ \\
\hline Chips AA7075 & 0.490 & 13.84 & 17.43 \\
\hline AA7075 1\% vol $\mathrm{ZrO}_{2}$ Hot Extrusion & 0.486 & 9.87 & 12.55 \\
\hline AA7075 1\% vol $\mathrm{ZrO}_{2}$ Hot Extrusion/HT & 0.488 & 16.27 & 20.63 \\
\hline $\begin{array}{c}\text { AA7075 1\% vol } \mathrm{ZrO}_{2} \text { Hot } \\
\text { Extrusion/ECAP }\end{array}$ & 0.478 & 15.11 & 19.42 \\
\hline $\begin{array}{c}\text { AA7075 1\% vol } \mathrm{ZrO}_{2} \text { Hot } \\
\text { Extrusion/ECAP/HT }\end{array}$ & 0.433 & 28.21 & 34.07 \\
\hline
\end{tabular}

Borblik et al. [19] proposed that the decreases in the size of sample resulted in decreases in all characteristics of the material surface. Luce et al. [20] reported the use of AFM to analyse sizes and other important characteristics for surface topography with ease in sample preparation for nano or microscales of the magnetic thin films.

\section{Conclusions}

This study focused on conducting a comprehensive investigation and computational analysis on the effects of preheating temperature $(\mathrm{T})$, preheating time $(\mathrm{t})$, and volume fraction (VF) of zirconium oxide on the mechanical properties and microstructure of the AA7075 composite manufactured by multiple processes. RSM revealed the main factor involved in achieving better UTS and microhardness was T and VF. On the other hand, $t$ affected density. A decrease in VF increased the mechanical properties up to $1 \mathrm{vol} \%$ of oxide. With $\mathrm{T}$ at $550{ }^{\circ} \mathrm{C}$, $\mathrm{t}$ at $1.58 \mathrm{~h}$ and $\mathrm{ZrO}_{2}$ at $1 \mathrm{vol} \%$, the maximum hardness of $95 \mathrm{HV}$, a density of $2.85 \mathrm{~g} / \mathrm{cm}^{3}$ and tensile strength of $487 \mathrm{MPa}$ were obtained. All the factors $\mathrm{T}, \mathrm{t}$, and VF are considered as important factors that affect the nanocomposite. UTS and microhardness were sensitive to heat treatment, as an increase of $22 \%$ and $29 \%$, respectively, was observed at high temperatures, efficiently consolidating the material. Density and microhardness of $2.9 \mathrm{~g} / \mathrm{cm}^{3}$ and $140 \mathrm{HV}$, respectively, were obtained after ECAP followed by the heat treatment process. Compression pressure and extrusion stress produced in these stages were sufficient to eliminate voids that increased mechanical properties but were incapable of improving chip welding.

Author Contributions: Conceptualisation, H.M.S.; writing-review and editing, M.H.R.; validation, S.M.T., C.N.A.J., A.H.M.A. and N.I.Z.; supervision, Z.L.; project administration, S.S.; methodology. All authors have read and agreed to the published version of the manuscript.

Funding: This research was funded by University Putra Malaysia, Grant No. 9686400.

Institutional Review Board Statement: Not applicable.

Informed Consent Statement: Not applicable.

Data Availability Statement: Not applicable.

Acknowledgments: The first author thanks the School of Graduate Studies for financial support to study at University Putra Malaysia. We acknowledge the use of facilities within the Centre for Graduate Studies, University Tun Hussein Onn Malaysia (UTHM), and Sustainable Manufacturing and Recycling Technology, Advanced Manufacturing and Materials Centre (SMART-AMMC), University Tun Hussein Onn Malaysia (UTHM). We equally acknowledge the College of Engineering, Wasit University, Kut 52001, Iraq for research collaborations.

Conflicts of Interest: The authors declare no conflict of interest. 


\section{References}

1. Sabbar, H.M.; Shamsudin, S.; Abbas, M.A.; Msebawi, M.S.; Mustapa, M.S.; Lajis, M.A.; Rady, M.H.; Al Alim, S. Study on the Wear Influence for Recycled AA6061 Aluminum $/ \mathrm{Al}_{2} \mathrm{O}_{3}$ Utilizing the Face Central-Full Factorial Technique (FCFFT). In Advances in Material Sciences and Engineering; Springer: Berlin, Germany, 2020; pp. 599-608.

2. Shamsudin, S.; Lajis, M.A.; Zhong, Z.W. Solid-state recycling of light metals: A review. Adv. Mech. Eng. 2016, 8, 1-23. [CrossRef]

3. Msebawi, M.S.; Murugesan, J.; Shamsudin, S.; Rady, M.H.; Sabbar, H.M.; Mustapa, M.S.; Lajis, M.A.; Abbas, M.A. Strength performance of micro alumina reinforced direct recycled aa6061 chips based matrix composite. Mater. Sci. Forum 2019, 961, 73-79. [CrossRef]

4. $\quad$ Rady, M.H.; Mustapa, M.S.; Harimon, M.A.; Ibrahim, M.R.; Shamsudin, S.; Lajis, M.A.; Wagiman, A.; Msebawi, M.S.; Yusof, F. Effect of hot extrusion parameters on microhardness and microstructure in direct recycling of aluminium chips. Materwiss. Werksttech. 2019, 50, 718-723. [CrossRef]

5. Al-alimi, S.; Lajis, M.A.; Shamsudin, S.; Chan, B.L.; Ismail, A.E.; Sultan, N.M. Development of metal matrix composites and related forming techniques by direct recycling of light metals: A review. Int. J. Integr. Eng. 2020, 1, $144-171$.

6. Liu, X.; Zhang, Z.; Hu, W.; Le, Q.; Bao, L.; Cui, J. Effects of Extrusion Speed on the Microstructure and Mechanical Properties of Mg9Gd3Y1.5Zn0.8Zr alloy. J. Mater. Sci. Technol. 2016, 32, 313-319. [CrossRef]

7. Sabbar, H.M.; Leman, Z.; Rady, M.H.; Shamsudin, S.; Tahir, S.M.; Jaafar, C.N.A.; Hanim, M.A.A.; Zahari, I.; Msebawi, M.S. Mechanical and physical properties of micro alumina reinforced direct recycled AA6061 chips based matrix by hot extrusion process. Int. J. Mech. Mechatron. Eng. 2020, 20, 32-41.

8. Fan, C.; Chen, X.; Zhou, X.; Ou, L.; Yang, J.; Peng, Y. Microstructure evolution and strengthening mechanisms of spray-formed 5A12 Al alloy processed by high reduction rolling. Trans. Nonferrous Met. Soc. China 2017, 27, 2363-2370. [CrossRef]

9. Al-Alimi, S.; Lajis, M.A.; Shamsudin, S. Solid-State Recycling of Light Metal Reinforced Inclusions by Equal Channel Angular Pressing: A Review. MATEC Web Conf. 2017, 135, 13. [CrossRef]

10. Shaeri, M.H.; Shaeri, M.; Ebrahimi, M.; Salehi, M.T.; Seyyedein, S.H. Effect of ECAP temperature on microstructure and mechanical properties of Al-Zn-Mg-Cu alloy. Prog. Nat. Sci. Mater. Int. 2016, 26, 182-191. [CrossRef]

11. Wagiman, A.; Mustapa, M.S.; Shamsudin, S.; Lajis, M.A.; Asmawi, R.; Harimon, M.A.; Yusof, F.; Rady, M.H. Effect of chip treatment on chip-based billet densification in solid-state recycling of new aluminium scrap. Lect. Notes Mech. Eng. 2020, 327-336. [CrossRef]

12. Rady, M.H.; Mustapa, M.S.; Shamsudin, S.; Lajis, M.A.; Masirin, M.I.M.; Wagiman, A. Effect of hot extrusion parameters on tensile strength and fracture behavior in direct recycling of aluminium alloy (6061) chips. Mater. Sci. Forum 2020, 975, 229-234. [CrossRef]

13. Wagiman, A.; Mustapa, M.S.; Asmawi, R.; Shamsudin, S.; Lajis, M.A.; Mutoh, Y. A review on direct hot extrusion technique in recycling of aluminium chips. Int. J. Adv. Manuf. Technol. 2020, 106, 641-653. [CrossRef]

14. Sabbar, H.M.; Leman, Z.; Shamsudin, S.B.; Tahir, S.M.; Aiza Jaafar, C.N.; Hanim, M.A.A.; Ismsrrubie, Z.N.; Al-Alimi, S. AA7075$\mathrm{ZrO}_{2}$ nanocomposites produced by the consecutive solid-state process: A review of characterisation and potential applications. Metals 2021, 11, 805. [CrossRef]

15. Rifai, M.; Miyamoto, H.; Fujiwara, H. The effect of ECAP deformation route on microstructure, mechanical and electrochemical properties of low CN Fe-20\%Cr alloy. Mater. Sci. Appl. 2014, 5, 568-578. [CrossRef]

16. Al-Alimi, S.; Lajis, M.A.; Shamsudin, S.; Yusuf, N.K.; Chan, B.L.; Hissein, D.D.; Rady, M.H.; Msebawi, M.S.; Sabbar, H.M. Hot extrusion followed by a hot ecap consolidation combined technique in the production of boron carbide (B4C) reinforced With aluminium chips (AA6061) composite. Mater. Tehnol. 2021, 55, 347-354. [CrossRef]

17. Oter, Z.C.; Coskun, M.; Akca, Y.; Sürmen, Ö.; Yılmaz, M.S.; Özer, G.; Tarakçı, G.; Koc, E. Benefits of laser beam based additive manufacturing in die production. Optik 2019, 176, 175-184. [CrossRef]

18. Xiao, Z.; Hu, J.; Liu, Y.; Dong, F.; Huang, Y. Segregation of Sc and its effects on the strength of Al $\Sigma 5$ (210) [100] symmetrical tilt grain boundary. Mater. Sci. Eng. A 2019, 756, 389-395. [CrossRef]

19. Borblik, V.; Korchevoi, A.; Nikolenko, A.; Strelchuk, V.; Fonkich, A. Fabrication of Nanostructured Objects by Thermal Vacuum Deposition of Ge Fabrication of Nanostructured Objects by Thermal Vacuum Deposition of Ge Films onto (100) GaAs Substrates. Nanosci. Nanoeng. 2016, 4, 22-30. [CrossRef]

20. Luce, A. Atomic Force Microscopy Grain Structure Characterization of Perpendicular Magnetic Recording Media. Process. Charact. 2007, 134-135. 